\title{
Synapsin III Controls Early Phases of Dopaminergic Neurons Development in Fishes and Mammals by Acting Upstream of BDNF and Cdk5 Signaling
}

Gaia Faustini

University of Brescia Department of Molecular and Translational Medicine: Universita degli Studi di Brescia Dipartimento di Medicina Molecolare e Traslazionale

Francesca Longhena

University of Brescia Department of Molecular and Translational Medicine: Universita degli Studi di Brescia Dipartimento di Medicina Molecolare e Traslazionale

\section{Alessia Muscò}

University of Brescia Department of Molecular and Translational Medicine: Universita degli Studi di Brescia Dipartimento di Medicina Molecolare e Traslazionale

\section{Federica Bono}

University of Brescia Department of Molecular and Translational Medicine: Universita degli Studi di Brescia Dipartimento di Medicina Molecolare e Traslazionale

\section{Edoardo Parrella}

University of Brescia Department of Molecular and Translational Medicine: Universita degli Studi di Brescia Dipartimento di Medicina Molecolare e Traslazionale

\section{Luca La Via}

University of Brescia Department of Molecular and Translational Medicine: Universita degli Studi di Brescia Dipartimento di Medicina Molecolare e Traslazionale

\section{Alessandro Barbon}

University of Brescia Department of Molecular and Translational Medicine: Universita degli Studi di Brescia Dipartimento di Medicina Molecolare e Traslazionale

\section{Marina Pizzi}

University of Brescia Department of Molecular and Translational Medicine: Universita degli Studi di Brescia Dipartimento di Medicina Molecolare e Traslazionale

\section{Franco Onofri}

University of Genoa Department of Experimental Medicine: Universita degli Studi di Genova Dipartimento di Medicina Sperimentale

\section{Fabio Benfenati}

Italian Institute of Technology: Istituto Italiano di Tecnologia

\section{Cristina Missale}


University of Brescia Department of Molecular and Translational Medicine: Universita degli Studi di Brescia Dipartimento di Medicina Molecolare e Traslazionale

\section{Maurizio Memo}

University of Brescia Department of Molecular and Translational Medicine: Universita degli Studi di Brescia Dipartimento di Medicina Molecolare e Traslazionale

\section{Daniela Zizioli}

University of Brescia Department of Molecular and Translational Medicine: Universita degli Studi di Brescia Dipartimento di Medicina Molecolare e Traslazionale

\section{Arianna Bellucci ( $\sim$ arianna.bellucci@unibs.it)}

University of Brescia Department of Molecular and Translational Medicine: Universita degli Studi di Brescia Dipartimento di Medicina Molecolare e Traslazionale https://orcid.org/0000-0002-9581-1919

\section{Research Article}

Keywords: Syn III, dopaminergic neurons, Attention deficits and hyperactivity disorder, neurodevelopment

Posted Date: December 30th, 2021

DOI: https://doi.org/10.21203/rs.3.rs-1174147/v1

License: (c) (1) This work is licensed under a Creative Commons Attribution 4.0 International License. Read Full License 


\section{Abstract}

Polymorphisms in the Synapsin III (Syn III) gene can associate with attention deficits and hyperactivity disorder (ADHD), a neurodevelopmental disorder characterized by alterations in the mesocorticolimbic and nigrostriatal dopaminergic pathways. In spite of evidence supporting that Syn III controls the development of cortical and hippocampal short-projecting neurons, whether it plays a similar role in midbrain dopaminergic neurons ( $\mathrm{mDN}$ ), owning extensively arborized long-distance multi-synaptic axonal projections, was unexplored.

Our studies on mDN development in zebrafish embryos exposed to Syn III gene knock-down (KD), Syn III knock-out (ko) mice and Syn III-deleted human induced pluripotent stem cells (iPSCs)-derived neurons disclose that Syn III governs early mDN developmental stages in fishes and mammals. Differently to what observed in cortical and hippocampal neurons, this Syn III function impinges on the upstream control of brain derived neurotrophic factor (BDNF)-mediated and cAMP-dependent protein kinase 5 (Cdk5)-stimulated dendrite development. These findings have significant implications for deciphering the basis of ADHD.

\section{Introduction}

Synapsin III (Syn III) is a neuronal phosphoprotein belonging to the Synapsins (Syns) family together with synapsin I (Syn I) and synapsin II (Syn II). Syn III is implicated in the development of cortical and hippocampal neurons [1-5] and controls striatal dopaminergic neurotransmission in the adult brain [57]. Moreover, it is involved in psychiatric and neurological disorders associated with dysfunctions of dopaminergic systems, including attention deficits and hyperactivity disorder (ADHD), schizophrenia, and Parkinson's disease (PD) $[5,8-10]$.

Certain human Syn III gene polymorphisms associate with ADHD onset and can even influence the response to the most effective ADHD treatment, methylphenidate (MPH), a key modulator of dopaminergic neurotransmission that, as we recently showed, can bind Syn III [9, 11-13]. ADHD is characterized by an impaired development of dopaminergic neurons, reflected by a marked alteration in brain dopamine (DA) synthesis and dopaminergic dysregulations [14-16]. This supports that Syn III could be also implicated in the development of midbrain dopaminergic neurons (mDN), that differently from cortical and hippocampal cells, are characterized by long-distance, extensively arborized multisynaptic axonal projections, connecting with diverse brain areas [17-20]. The mDN of the ventral tegmental area (VTA) innervate the ventral striatum or the prefrontal cortex (mesocorticolimbic pathways) and control reward mechanisms, reinforced learning, emotion, motivation and executive functions. The $\mathrm{mDN}$ of the substantia nigra (SN) pars compacta instead project to the dorsal striatum (nigrostriatal pathway) and regulate voluntary movements [21]. Both the mesocorticolimbic and nigrostriatal pathways exhibit alterations in ADHD patients [15, 16, 22]. 
Here, we studied dopaminergic neurons development zebrafish (Danio Rerio) embryos exposed to Syn III gene knock-down (KD), Syn III knockout (ko) mice and human induced pluripotent stem cells (iPSCs)derived $\mathrm{mDN}$ subjected to Syn III gene silencing. Our results show that Syn III governs the early stages of $\mathrm{mDN}$ development in fishes and mammals. In zebrafish larvae, the dopaminergic developmental delay associated with Syn III gene KD induced an ADHD-like phenotype and was rescued by the expression of rat Syn III mRNA. In mammals, the Syn III-dependent regulation of mDN dendrite development appeared related with the upstream control of brain derived neurotrophic factor (BDNF)-mediated dendrite elongation. This collimated with the disruption of cAMP-dependent protein kinase 5 (Cdk5)-stimulated dendrite development in the primary mDN neurons of Syn III ko mice. Our results also support that in mammals, the Syn III deletion-dependent mDN early developmental deficits can be progressively rescued in adulthood. However, the slower retrieval of pars reticulata $(p r)$ dopaminergic SN neurons dendritic arborizations, when compared to the more rapid rescue of their number and striatal axonal projections observed in Syn III ko mice, suggest that the mDN developmental delay potentially associating with Syn III polymorphisms could still generate significant alterations in the normal integration of basal ganglia circuits, thus leading to ADHD manifestation.

\section{Materials And Methods}

\section{Animals}

All the experiments on zebrafish were performed with embryos under the age of $5 / 7$ days postfertilization (dpf), in accordance with the standard rules defined by the Local Commitment for animal Health (Project 211B5-10) and following the Italian and European rules on animal care (EU directive 2010/63/EU). Wild type AB strain and the transgenic lines $\operatorname{Tg}$ (neurod1:eGFP) and $\operatorname{Tg}$ (ngn1:eGFP) were used for all the experiments. Fishes were kept in $3 \mathrm{~L}$ tanks with $28^{\circ} \mathrm{C}$ warm water in a circulating system maintained at $\mathrm{pH} 7.0-7.5$ and conductivity in a range of 450-550 $\mu \mathrm{S}$. Adult animals were maintained under a 14/10 hours light/dark cycle and fed three times per day with a combination of granular food and freshly prepared Artemia. Breeding of adult zebrafish was carried out by natural crosses and embryos were collected; they were staged according to established protocols [23]. Fresh spawned embryos produced in the morning were collected in Petri dishes containing fish water $(0.1 \mathrm{~g} / \mathrm{L}$ Instant Ocean Sea Salts, $0.1 \mathrm{~g} / \mathrm{L}$ Sodium Bicarbonate, $0.19 \mathrm{~g} / \mathrm{L}$ Calcium Sulfate, $0.2 \mathrm{mg} / \mathrm{L}$ methylene blue in reverse osmosis water) until the desired developmental stage was reached and for further experiments (microinjection, dose-curve and morphological observations). To examine post-gastrulation stages for WISH experiments, fish water was added by 0,004\% 1-phenil-2-thiourea (PTU, Sigma-Aldrich, St. Louis, MO, USA) solution.

C57BL/6J wild type (wt) and Syn III ko mice (a kind gift of Prof. Fabio Benfenati, Italian Institute of Technology, Genova, Italy) were bred at the animal house facility at the Department of Molecular and Translational Medicine of University of Brescia. Animals were maintained under a 12h light-dark cycle at a room temperature (rt) of $22^{\circ} \mathrm{C}$ and had ad libitum food and water. All experiments were made in accordance to the Directive 2010/63/EU of the European Parliament and of the Council of 22 September 
2010 on the protection of animals used. All experimental and surgical procedures conformed to the National Research Guide for the Care and Use of Laboratory Animals were approved by the Animal Research Committees of the University of Brescia (Protocol Permit 719/2015-PR). All achievements were made to minimize animal suffering and to reduce the number of animals used. C57BL/6J wt mice (Charles River, Wilmington, MA), and Syn III ko animals on C57BL/6J background [24] were used in this study at 0,2 and 10 months of age.

\section{Bioinformatic analysis of Syn III}

The sequence of the genes encoding for Syn III in humans (SYN3), mouse or rat (Syn3) were assembled using ENSEMBL and BLAST searches within the Zebrafish Genome Browser (www.ensembl.org) were used to identify one homologous sequence on chromosome 4 where the zebrafish Syn III gene (syn3) is located. For the in silico analysis we used the following accession numbers: ENSDART000000157825.1 and ZFIN ZDB-GENE141212-325. Nucleotide and amino acid sequences were compared to the nonredundant sequences present at the National Center for Biotechnology Information (NCBI) using the Basic Local Alignment Search Tool (BLAST). Multiple sequences alignment was performed using the CLUSTALW software [25]. The following accession numbers of Syn III genes were used: human (NP_003481.3), mouse (NP_038750.2) and zebrafish (NP_001340893.1). To find evidence for the conservation of synteny, we compared genomic regions neighboring the zebrafish Syn III to the genes neighboring human and mouse Syns. Putative orthologs for each zebrafish gene were located on the human and mouse map using the Genomicus (http://www.genomicus.biologie.ens.fr /genomicus100.01/cgi-bin/search.pl) informatic tool.

\section{Morpholino microinjections and zebrafish phenotypic assessment}

To KD the expression of Syn III gene, a splice-inhibiting morpholino was used to knockdown syn3 expression (Syn III-MO) (5'-TCGATAACTAAGCGATGCCATCTGT-3') (GeneTools, LCC) in order to target the intron1-exon1 junction of immature mRNA and produce exon skipping in mRNA maturation by inducing the retention of exon1. A standard non-targeting morpholino (ST-MO) (5'-

CCTCTTACCTCAGTTACAATTTATA-3') was used as control (Gene Tools). We prepared the injection solution by diluting the morpholino stock solution ( $1 \mathrm{mM}$ ) with $10 \%$ phenol red and water to obtain the desired concentration to test a dose-curve. The following concentrations of oligo-morpholino were injected into embryos at 1-2 cell stage to determine the optimal concentration: $0.3,0.5,1,1.5$ and 2 $\mathrm{pmol} / \mathrm{embryo}$. The final concentration of $1 \mathrm{pmol} / \mathrm{embryo}$ (corresponding to $8 \mathrm{ng} / \mathrm{embryo}$ ) was used for all experimental procedures. Four $\mathrm{nl}$ of $1 \mathrm{pmol} / \mathrm{embryo}$ were injected into 1-2 cell stage embryos by Eppendorf FemtoJet Micromanipulator 5171. Injected embryos were then collected in Petri dishes and maintained in fish water at $28^{\circ} \mathrm{C}$. To avoid pigmentation process, $0.004 \%$ PTU was added to fish water at 20 hours post-fertilization (hpf) and development and morphological features were evaluated at 24 and 48 hpf. Images were taken using Zeiss AxioZoom V16 equipped with Zeiss Axiocam 503 colour digital camera (Carl Zeiss, Germany) and processed using Zen Pro software (Carl Zeiss). All experiments were repeated at least three times and altogether more than 150 of each type were viewed. 


\section{Whole-mount in situ hybridization}

Whole-mount in situ hybridization (WISH) was performed according to a standard protocol [26]. Briefly, embryos were collected, dechorionated and incubated at $28^{\circ} \mathrm{C}$ at different stages. They were then fixed for 2 hours with 4\% paraformaldehyde (PFA) in PBS at RT, dehydrated through an ascending (25\%-50\%-75\%) PBS/methanol solutions and stored at $-20^{\circ} \mathrm{C}$. After treatment with $10 \mu \mathrm{g} / \mathrm{mL}$ proteinase $\mathrm{K}$ (Roche, Switzerland), the embryos were hybridized overnight at $68^{\circ} \mathrm{C}$ with $1 \mathrm{ng} / \mu \mathrm{l}$ digoxygenin (DIG)labeled RNA probes kindly provided by prof. Franco Cotelli of the University of Milan (Italy). Embryos were washed with ascending scale of Hybe Wash (50\% deionized formamide, 5X SSC buffer, $0.1 \%$ Tween 20, adjusted to $\mathrm{pH} 6.0$ by adding citric acid)/PBS $1 \mathrm{X}$ and SSC (Sodium-citrate Buffer, Ambion, USA)/PBS then incubated with anti-DIG antibody conjugated with alkaline phosphatase (1:10000, GmbH, Germany) overnight at $4^{\circ} \mathrm{C}$. The staining was performed with NBT/BCIP (blue staining solution, Roche) alkaline phosphatase substrates. WISH images were taken with ZEISS Axio Zoom V.16 microscope (Carl Zeiss) equipped with Zeiss Axiocam 506 color digital camera and processing using Zen Pro software. Quantification of WISH pictures was performed with ImageJ software (NIH, Bethesda, USA) as described by [27]: a region of interest (ROI) ranging from the top of the head to mid-yolk was selected in 8-bit pictures. Due to the widespread distribution of the colorimetric signal across the embryo structure, background intensity measurement was carried out in blank embryos lacking incubation with RNA probe. The following probes were used: neurogenin 1 (ngn1); islet-1; glial fibrillary acidic protein gene (gfap).

\section{In vitro generation of rat Syn III mRNA expression plasmid for zebrafish transfection}

A recombinant plasmid containing the coding region of rat Syn III mRNA (p3x-FLAG-CMV-14-rat Syn III, a kind gift of Dr. Franco Onofri, University of Genova, Italy) was digested with Xba I/ Hind III restriction enzymes and subcloned in pCS2+ plasmid (a kind gift of Prof. Franco Cotelli, University of Milan). The resulting linearized plasmid was transcribed with T7 RNA polymerase using the mMESSAGE mMACHINE T7 Transcription Kit (ThermoFisher Scientific, Massachusetts, USA, AM1344) according to manufacturer's protocol. The product was quantified by mySPEC spectrophotometer (VWR International, Milan, Italy) and used for microinjections. A dose-response curve was performed to establish the proper amount of mRNA (100 pg/embryo) to be injected to avoid the appearance of aberrant phenotypes. $100 \mathrm{pg}$ of rat Syn III mRNA were injected alone or co-injected with Syn III-MO at 1-2 cell stage embryos.

\section{Acridine orange staining}

To analyze the level of cell death, acridine orange staining was performed using a standard protocol [28]. Embryos at 24 and $48 \mathrm{hpf}$ were dechorionated and incubated for 30 minutes in fish water containing acridine orange staining solution (10 mg/L). Embryos were then rinsed three times in fish water, mounted using $80 \%$ glycerol and quickly imaged using epifluorescent microscope with green fluorescence filter (Zeiss AxioZoom V16 equipped with Zeiss Axiocam 506 color digital camera and processed using Zen Pro software, Carl Zeiss). The acridine orange fluorescence intensity was quantified by using ZF-Mapper software. 


\section{Immunofluorescence assay}

For TH immunofluorescence, $48 \mathrm{hpf}$ embryos were fixed in 4\% PFA for two hours at it, then rinsed twice in PBS for 1 hour. Embryos were permeabilized in 10\% methanol in PBS for 1 hour under gentle agitation and non-specific binding was blocked overnight in 10\% Normal Goat Serum (NGS), $1 \%$ BSA in PBS/Triton $X-1000.3 \%$. The embryos were incubated for 72 hours with rabbit anti-tyrosine hydroxylase (TH) (1:200, ab152, Merck Millipore, Burlington, Massachusetts, USA) primary antibody in blocking solution at $4^{\circ} \mathrm{C}$. After three washes in PBS for 1 hour, samples were incubated with the anti-rabbit Cy3 (1:100, 111-165144, Jackson Immunoresearch, Cambridge, UK) secondary antibody diluted in 10\% NGS, 1\% BSA in PBS for 40 hours at $4^{\circ} \mathrm{C}$ and then rinsed several times in PBS. TH-stained embryos were visualized using Zeiss LSM880 confocal microscope (Carl Zeiss).

\section{Light-sheet imaging}

For light-sheet imaging, zebrafish embryos at the desired developmental stage were manually dechorionated and anesthetized in $0.04 \mathrm{mg} / \mathrm{L}$ tricaine and mounted in a glass capillary containing $1 \%$ low melting agarose (Thermo Fisher Scientific). After polymerization, capillaries were located into the imaging chamber. Images were acquired with Zeiss Light-sheet V1 (Carl Zeiss) using a 10x detection objective and laser sets at $488 \mathrm{~nm}$. 3D movies were created using Arivis software (Arivis AG, Munich, Germany).

\section{Confocal microscopy}

For confocal imaging of zebrafish embryos, these were fixed overnight in a PFA-based solution (25\% PFA, $0.03 \mathrm{~g} / \mathrm{mL}$ sucrose, $0.4 \%$ glutaraldehyde in PBS), then washed twice in PBS and kept in the same fixative solution with half the PFA, for at least 24 hours. The yolk was then removed from the selected embryos to avoid autofluorescence. The embryos were mounted on glass slides using Mowiol ${ }^{8}$ 4-88 mounting medium. The slides were observed by a LSM880 Zeiss confocal laser microscope with the laser set on $\lambda$ $=488 \mathrm{~nm}$. Z-stack images of the head and tile scan Z-stack images of whole embryos were taken with a 4 $\mu \mathrm{m}$ interval. Images were then processed using ZEISS ZEN Imaging Software to obtain the maximum intensity projection image. For the enhanced green fluorescent protein (eGFP) signal quantification of the diencephalon, 20 to 27 embryos were analyzed three times by drawing the area including the diencephalon. The average axon length of the embryos was assessed by quantifying the length of the 5th -to-16th projection of the spinal cord neurons of 15 embryos for each condition by using ImageJ Software's plugin, NeuronJ [29, 30].

\section{Immunohistochemistry and brightfield microscopy on mouse brain sections}

Newborn pups were dislocated and fix in 4\% PFA for $6 \mathrm{~h}$. Two- and 10-month-old mice were anaesthetized by intraperitoneal (i.p.) injection of chloral hydrate $(400 \mathrm{mg} / \mathrm{kg})$ (Sigma-Aldrich) and were perfused transcardially by using a 4\% PFA Immunofix solution (Bio-optica, Milan, Italy). After $4 \mathrm{~h}$ of post-fixation, brains were incubated in a solution of PBS with high salt concentration $\left(\mathrm{NaOH} 200 \mathrm{mM}, \mathrm{NaH}_{2} \mathrm{PO}_{4} 245\right.$ 
$\mathrm{mM}, \mathrm{NaCl} 0.9 \%$ ) containing $18 \%$ sucrose for at least $24 \mathrm{~h}$, then $30 \mu \mathrm{m}$ coronal sections were cut with a cryostat (Leica Biosystems, Milan, Italy) and conserved in $60 \%$ glycerol. Sections of the substantia nigra and striatum were permeabilized with $20 \%$ methanol and $5 \% \mathrm{H}_{2} \mathrm{O}_{2}$, washed and incubated with primary antibody (TH, AB152, Merck Millipore) overnight (ON) at $4^{\circ} \mathrm{C}$. On the following day, sections were washed and probed with anti-rabbit biotinylated secondary antibody for $45 \mathrm{~min}$ at rt. This was followed by gentle washing, incubation with avidin-biotin complex ( $A B C$ kit, Vector Laboratories, Burlingame, $C A$ ) at it for 45 min and 3,3'-diaminobenzidine (DAB) staining (Vector Laboratories) for $5 \mathrm{~min}$. Finally, sections were washed, dehydrated, mounted with Vectamount mounting medium (Vector Laboratories) and were observed by means of an inverted light/epifluorescence microscope (Olympus IX50; Olympus, Milan, Italy).

\section{Nigral TH-positive stereological quantification and analysis of TH density in the pr and striatal sections}

The number of TH-immunopositive cells was stereologically estimated by double blind cell counting in bright field microscopy using an optical fractionator method, as previously described [24]. Neurons from the SN pars compacta were analyzed with an inverted microscope (Zeiss Axiovert S100 and camera PCO Sensicam) interfaced with a PC running the StagePro module of Image-ProTM Plus software (version 6.2, Media Cybernetics, Inc.). The entire extension of mesencephalon was cut into sections. Three sections (30 $\mu \mathrm{m}$ thick) were examined every $150 \mu \mathrm{m}$ in a rostro-caudal extension. Tyrosine hydroxylaseimmunoreactive cells lateral to the medial terminal nucleus of the accessory optic tract, which defines the medial border of the SN pars compacta were counted. The ventral tegmental area was thereby excluded from these cell counts.

The optical density of TH-positive area of the prwas examined from digitized images using ImageJ software. Brains from five mice (ten sections from each mouse) were analyzed by examining an average of 10 fields per section for 2 and 10 months of age and 5 sections for newborn pups. Data from nigral TH-positive cell counts and from the analysis of TH-positive area were expressed as \% changes versus the mean of wt controls.

The optical density of striatal TH-positive area was examined from digitized images using ImageJ software. Brains from 2 and 10 months-old mice (10 sections from each mouse, $n=3$ for each group) were analyzed by examining an average of 15 fields per section. Brains from newborn mice ( 5 sections from each mouse, $n=3$ for each group) were analyzed by examining an average of 2 fields per section. Data from striatal TH-positive area were expressed as percent changes versus the mean of the respective wt controls.

\section{Clarification of striatal tissues and two-photon microscopy}

Brains from newborn mice were fixed for $8 \mathrm{~h}$ in Immunofix and clarified with the X-Clarity system (Logos Biosystem, South Korea). Briefly, whole brains were polymerized with acrylamide "hydrogel solution" for 3 $\mathrm{h}$ at $37^{\circ} \mathrm{C}$ with vacuum followed by the passive clarification for $48 \mathrm{~h}$ at $37^{\circ} \mathrm{C}$ in "clearing solution". 
Brains were subjected to deep-tissue TH immunolabeling by staining with TH antibody (dilution 1:100, Merck Millipore) in PBS/0.3\% Triton for 3 days, 1 day of washing followed by incubation with anti-rabbit Alexa 488 for 3 days (Jackson Immunoresearch).

Brains were then observed by a two-photon upright LSM 880 Zeiss microscope equipped by W PlanApochromat 20x/1.0 DIC (UV) VIS-IR M27 $75 \mathrm{~mm}$ objective. The fluorochrome was excited with the IR laser set at $860 \mathrm{~nm}$. Z-stack were set with the height of the sections scanning $=\sim 1 \mu \mathrm{m}$. Images were then reconstructed using Zen lite 2.3 (Carl Zeiss).

\section{Behavioral tests}

Analysis of spontaneous head-tail coil spontaneous movements, corkscrew swimming and touch-evoked tests in Zebrafish embryos.

Zebrafish embryos were injected with Syn III-MO, ST-MO (control) and incubated in fish water, non-injected (NI) embryos were used as negative control. Embryos were kept at $28^{\circ} \mathrm{C}$ until reaching the correct stage of development to carry out the test. At $21 \mathrm{hpf}, 40$ injected embryos (respectively ST-MO and Syn III-MO) and $\mathrm{NI}$ were observed for head-tail coil spontaneous contractions for 1 minute under microscope. The total number of head-tail coil movements (tail flip) of three independent experiments was recorded for each embryo, the average was calculated, and a box diagram was plotted for injected and not injected embryos.

At 72 hpf, 40 embryos for each type were subjected to touch-evoked test, following the protocol [31] with slight modifications. A motility wheel consisting of four concentric circles of increasing diameter $(5,10$, $15,20 \mathrm{~mm}$ ) was placed under the microscope and centered at the bottom of a $60 \mathrm{~mm} \varnothing$ Petri dish containing fish water. Each embryo was placed in the center of the inner circle and the tail was gently stimulated with a poker tool, the distance it swam in the predetermined concentric circles was recorded. If the embryo could not cross the first circle after multiple attempts (5 attempts), it was determined as incapable of exiting the circle. Once data of the distance swam all 25 embryos of each group were obtained, the percentage of embryos crossing each predetermined concentric circle were calculated.

At 2, 3 and $4 \mathrm{dpf}$, the corkscrew swimming (spiraling, whirling) movements were analyzed. Briefly, 40 embryos per type were observed for 3 min under the microscope. The total number of corkscrew movements of 3 independent experiments was recorded for each embryo, the average was calculated and a box diagram was plotted for injected and non-injected embryos.

Accelerating rotarod test and pole test in adult C57BL/6J and Syn III ko mice.

The training trials of rotarod test were performed at day 0 by setting a slow speed $(5 \mathrm{rpm})$ on $3 \mathrm{~cm}$ diameter 47650 Rota-Rod (Ugo Basile, Milan, Italy). The animals were placed back and habituated to stay on the drum for $3 \mathrm{~min}$. The learning session is concluded after remaining $180 \mathrm{~s}$ on the drum and repeated for at least 3 times every 30 min since all the trial were completed. The following day the accelerating rotarod protocol was tested by increasing the speed from 4 to $40 \mathrm{rpm}$ up to $300 \mathrm{~s}$ and the latency to fall 
was recorded automatically from the instrument. The number of learning trials, the best trial and the mean trial, as well as the latency to fall for each trial were reported by examining 4/10 mice per condition.

The pole test was performed by placing the mice head-upward on the top of a vertical pole with a rough surface ( $2 \mathrm{~cm}$ diameter, $50 \mathrm{~cm}$ height). The pole was placed in the home cage and a habituation period was waited by placing animals on the cage of the pole 3 min before the test. A learning session was performed for 5 times every $30 \mathrm{~min}$. The following day, 3 trials every 30 min were recorded and the time to descend of the best trial and mean trial were evaluated with the maximal severity set at $100 \mathrm{~s}$. Results from $3 / 7$ mice were averaged.

\section{Western blot analysis}

Fresh frozen zebrafish embryos pools (10 embryos for each experimental condition) or tissues from the striatum and midbrain of either Syn III ko or wt mice collected from mouse brains after cervical dislocation were used. Total proteins were extracted with Radioimmunoprepitation Assay (RIPA) buffer made up by $50 \mathrm{mM}$ Tris- $\mathrm{HCl}$ pH 7.4, $150 \mathrm{mM} \mathrm{NaCl}, \mathrm{NP}-40$ 1\%, sodium deoxycholate $0.1 \%$, sodium dodecyl sulfate (SDS) $0.1 \%, 1 \mathrm{mM} \mathrm{NaF}, 1 \mathrm{mM} \mathrm{NaVO}_{4}$ plus complete protease inhibitor mixture (Roche Diagnostics, Mannheim, Germany). Protein concentration in the samples was measured by using the BioRad DCTM protein assay kit (Bio-Rad Laboratories, Milan, Italy). Equal amounts of proteins ( $30 \mu \mathrm{g}$ for mouse brain samples, $60 \mu \mathrm{g}$ for zebrafish embryos samples) were run on $10 \%$ polyacrylamide gels and transferred onto polyvinylidene fluoride (PVDF) membrane. Densitometric analysis of the bands were performed by using ImageJ Software and all bands were normalized to Glyceraldehyde 3-phosphate dehydrogenase (GAPDH) or a-Tubulin levels as a control of equal loading of samples in the total protein extracts. For densitometry analysis of bands, each experimental condition was performed in quadruplicate and the resulting data were subjected to statistical analysis. The primary antibodies used for western blot studies and their working dilutions are listed in Table 1.

Table 1

List of the primary antibodies used in the western blot studies and of their working dilutions.

\begin{tabular}{|llll|}
\hline Antibody & Manufacturer & Species & Dilution \\
\hline Syn III & Synaptic System & Rabbit & $1: 2000$ \\
\hline Syn II & Synaptic System & Rabbit & $1: 2000$ \\
\hline Syn I & Synaptic System & Rabbit & $1: 2000$ \\
\hline TH & Merck Millipore & Rabbit & $1: 2000$ \\
\hline BDNF & abcam & Rabbit & $1: 1000$ \\
\hline GAPDH & Sigma-Aldrich & Mouse & $1: 5000$ \\
\hline a-Tubulin & Sigma-Aldrich & Mouse & $1: 2000$ \\
\hline
\end{tabular}

\section{Primary midbrain neurons and treatments}


Primary midbrain neurons were dissected from C57BL/6J wt control mice and Syn III ko mice at embryonic day 12.5. After dissociation with Accumax (Sigma-Aldrich), the single cells were re-suspended in whole culture medium composed of Neurobasal ${ }^{\mathrm{TM}}$ medium (ThermoFisher Scientific) containing 100 $\mu \mathrm{g} / \mathrm{ml}$ penicillin, $100 \mu \mathrm{g} / \mathrm{ml}$ streptomycin (Sigma-Aldrich), $2 \mathrm{mM}$ glutamine (EuroClone, Milan, Italy) and $2 \%$ B27 supplement (Thermo Fisher Scientific) and then centrifuged. Cell counts and viability assays were performed using the Trypan Blue exclusion test. Neurons were seeded onto glass coverslides in 24well plates coated with $12 \mu \mathrm{g} / \mathrm{ml}$ poly-D-lysine. Cells were maintained at $37^{\circ} \mathrm{C}$ under a humidified atmosphere of $5 \% \mathrm{CO}_{2}$ in Neurobasal medium for 1-3-10 days in vitro (div).

DA $(0.1 \mu \mathrm{M})$ diluted in $1 \mathrm{mg} / \mathrm{ml}$ ascorbic acid [32] and $10 \mathrm{ng} / \mathrm{ml} \mathrm{BDNF}$ diluted in PBS/0.1\% BSA were used to treat midbrain neurons. In particular, DA or BDNF were directly diluted in whole culture medium, and this was used to re-suspend cell pellets before seeding. The DA or BDNF additioned whole culture medium was maintained until div 1 , when cells were fixed with Immunofix for $15 \mathrm{~min}$ and subjected to morphological analysis. Control cells were re-suspended and cultured in whole culture medium without DA or BDNF addition up to fixation at div 1 . The $1 \mu \mathrm{M}$ roscovitine treatment (prepared from a $100 \mathrm{mM}$ stock diluted in DMSO) was performed directly adding in the culture medium at div 3 for $24 \mathrm{~h}$ fixing neurons at div 10. Control cells wells were subjected to DMSO additions without drugs.

\section{Immunocytochemistry}

After fixation neurons were subjected to permeabilization with $20 \%$ methanol plus endogenous peroxidases inactivation in $5 \% \mathrm{H}_{2} \mathrm{O}_{2}$, and then washed and incubated with $\mathrm{TH}$ antibody over night at $4^{\circ} \mathrm{C}$. On the following day, cells were washed and probed with anti-rabbit biotinylated secondary antibody for $45 \mathrm{~min}$ at $\mathrm{rt}$. This was followed by gentle washing, incubation with avidin-biotin complex at it for $45 \mathrm{~min}$ and DAB staining for 5 min. Finally, sections were washed and observed by means of an inverted light/epifluorescence microscope.

\section{Sholl analysis on primary mDN}

The Sholl analysis of TH-positive mDN neurons was performed manually by using image J software. Neurons were randomly chosen and the number of intersections of the neurite tree with increasing circular circles from the center of the soma was counted every $10 \mu \mathrm{m}$ by using the concentric circle mask. The number of branches from the cell body were manually counted and the area was measured by drawing the shape of the soma and averaged.

\section{Human iPSCs culture, transduction and differentiation into $\mathrm{mDN}$}

Two iPSCs control cell lines (CTRL-1 and CTRL-2) derived from adult individuals without any known disease were evaluated in this study and have been previously published showing a complete analysis of pluripotent stem characteristics [33, 34]. Informed consent was obtained from all healthy donors involved in our study [33, 34]. iPSCs were cultured on Matrigel (BD Biosciences, USA)-coated 6-well tissue culture plates (Corning, New York, USA) in StemFlex medium (Gibco, Termo Fisher Scientific) changed every other 
day. Cells were passaged every 3-4 days using ReleSR (Stemcell technologies, Vancouver, Canada) and replated onto fresh Matrigel-coated plates. Cells were cultured at $37^{\circ} \mathrm{C}$ in $5 \% \mathrm{CO}_{2}$ and in a humidified atmosphere.

For SYN3 silencing, iPSCs were infected with an adeno-associated viral vector (AAV) expressing either a short hairpin RNA (shRNA) serotype 2/ 6 driven by the U6 promoter acquired by Vector biolabs (Malvern, PA, USA) silencing SYN3 (AAV-shSynIII) or non-silencing RNA sequences (AAV-shNSC) with a multiplicity of infection (MOI) of $1 \times 10^{2}$ for $24 \mathrm{~h}$ at $37^{\circ} \mathrm{C}$ and $5 \% \mathrm{CO}_{2}$. After $24 \mathrm{~h}$, the medium containing the viral particles was removed and replaced with fresh medium. SYN3 silencing was checked 6 days post transduction by western blot analysis.

Differentiation of iPSCs into mature mDN were obtained by using a dual-SMAD inhibition protocol [35] with some modifications, as previously described [33, 34, 36]. Cells were then fixed at different time points ( $\operatorname{div} 25$, div 40 , div 50 ) during the differentiation process and analysed by immunocytochemistry for morphological parameters and by western blot for SYN3 silencing.

\section{Morphometric analyses on TH-positive iPSCs-derived mDN}

Neurons were fixed using 4\% PFA and stained for TH antibody as described above. Digital images of the immunocytochemical assays were captured with an Olympus IX51 microscope connected to an Olympus digital camera and analysed using ImageJ software. The morphologic indicators of structural plasticity were: maximal dendrite length, primary dendrite number and soma area. Three slides per treatment group were examined to obtain measurements from at least 30 neurons.

\section{Statistical analysis}

The data are reported as representative of two or more experiments with similar results, depending on the number of embryos analyzed in each experiment. Statistically significant differences between groups were calculated by one-way ANOVA coupled with either Newman-Keuls or Tuckey's post-comparison tests or Student's t-test. Statistically significance was established at $p<0.05$.

\section{Results}

\section{Zebrafish embryos injected with syn3 KD morpholino display an overt developmental delay}

It has been described that in zebrafish the gene encoding for Syn III (syn3) is highly expressed during the early phases of development from 16 to $72 \mathrm{hpf}$ [37]. In situ hybridization studies allowed to visualize the Syn III mRNA in the midbrain, hindbrain and in various regions of the anterior central nervous system (CNS), diencephalon, tegmentum and, to a lesser extent, in dorsal and ventral spinal cord cells [37]. Of note, most of these areas contain DA neurons [38-41]. 
To assess the impact of Syn III in zebrafish neurodevelopment we designed a splice-inhibiting morpholino to knockdown syn3 expression (Syn III-MO) at different stages of development. Dose-response studies to investigate the impact of Syn III-MO on embryo's survival, showed a significant concentration-dependent increase in mortality at $48 \mathrm{hpf}$ in the embryos injected with Syn III-MO when compared to those inoculated with either a ST-MO or NI embryos (Fig. 1a,b). From these experiments, the intermediate concentration of $1.0 \mathrm{pmol} / \mathrm{embryo}$, inducing morphological changes and about a $25 \%$ of embryos death when compared to $\mathrm{NI}$ or ST-MO, was selected as optimal dose for the subsequent studies.

The analysis of pooled embryos injected with the dose of $1.0 \mathrm{pmol} / \mathrm{embryo}$ subjected to Acridine orange staining showed that Syn IIIMO-injection did not cause cell death events with respect to ST-MOinoculated or NI viable embryos at 48 hpf (Fig. 1c).

The phenotype induced by Syn III-MO at $48 \mathrm{hpf}$ was scored according to the severity of the morphological features of embryos. In particular, the $65 \%$ of embryos $(n=256 / 399)$, which exhibited perturbed brain morphology, with smaller brain size and eyes, shorter and thinner tail, as well as defective somite development, was included in the mild phenotype category. The remaining $35 \%$ of embryos $(n=143 / 399)$, characterized by dramatic alterations of the CNS structures, with severe perturbation of the anteroposterior axis, cardiac edema and compromised somite development, was included in the severe phenotype category (Fig. 1a,d). ST-MO-inoculated and NI embryos did not exhibit significant phenotypic alterations. We then assessed the percentage of phenotypic manifestation of head malformations, alterations in the anteroposterior axis, hyperactive movements and abnormal heartbeat in both mild and severe phenotype embryos. We found that syn3 KD impacted on head morphology, heartbeat and induced hyperactive movements in a similar manner in both phenotypes, while anteroposterior axis malformations were accentuated in the embryos with the severe phenotype (Fig. 1e). Based on these observations, we selected the embryos with mild phenotype as the model to be used for all further experiments.

In order to probe whether Syn III deletion impinges on zebrafish neurodevelopment, we assessed the expression of specific markers in the ventral telencephalon and dorsal diencephalon by performing WISH. In particular, we studied $n g n 1$, which is expressed by basal forebrain DA neuronal progenitor cells either in the proneural clusters detectable at $16 \mathrm{hpf}$ or in the ventricular proliferative zones, and mitotic cells that can be visualized at $24 \mathrm{hpf}[42,43]$. At $16 \mathrm{hpf}$, the Syn II-MO-injected morphants ( $=45 / 57)$ exhibited a significant reduction in the expression of $n g n 1$ in the main anterior developing structures, such as cranial ganglia and diencephalic neurons (Fig. 2a,b). At $24 \mathrm{hpf}$, the significant decrease of $n g n 1$ expression associated with syn3 KD involved basal forebrain structures including the telencephalon, diencephalon, midbrain and hindbrain (Fig. 2a,c). The WISH-based analysis of the expression of a LIM/homeobox gene with important developmental and regulatory function, Islet-1, in forebrain and midbrain neurons, as well as in cranial motoneurons at $30 \mathrm{hpf}$ showed that Syn III-MO injection significantly reduced Islet-1 expression in diencephalic, telencephalic areas and hindbrain (Fig. 2d,f). 
Since Syns are also expressed within developing astrocytes [44] and astrocyte-derived Syn I can promote neurite outgrowth [45], we also checked whether syn3 KD could impact gfap expression at $30 \mathrm{hpf}$. At this early developmental stage $g f a p$ is expressed in both neuronal and glial precursor cells although it can be considered a specific glial marker from around $72 \mathrm{hpf}$ onward [46]. Interestingly, we observed that Syn IIIMO-injected embryos exhibited a significant reduction of gfap expression when compared to ST-MOinjected embryos (Fig. 2e,g).

To gain further insights into the involvement of Syn III in zebrafish neurogenesis and neurodevelopment, we used two transgenic lines expressing eGFP, under the control of the promoters of two transcription factors known to play important role in neuronal development. These were the neuronal differentiation 1 (neurod1), referred as $\mathrm{Tg}$ (neurod1:eGFP) [47], and ngn 1 which is a neurod1 upstream regulator, referred as $\operatorname{Tg}(n g n 1:$ eGFP) [48]. The expression of neurod 1 and $n g n 1$ correlate and partially overlap in many zebrafish brain regions, with $n g n 1$ being more restricted toward the ventricular proliferative zones and neurod 1 extending more laterally [49].

We found that in ST-MO-injected Tg(ngn1:eGFP) control embryos at $48 \mathrm{hpf}$, the eGFP signal localized in CNS regions corresponding to forebrain (ventral and dorsal diencephalon) and posterior tuberculum, as well as in motor neurons of the trunk as expected [48]. Interestingly, in the Syn III-MO-injected $\mathrm{Tg}$ (ngn1:eGFP) embryos the eGFP signal was not detectable in spinal cord motor neurons projections, supporting the occurrence of a neurodevelopmental deficit (Fig. 3a). The analysis of eGFP localization in the ST-MO-injected Tg(neurod1:eGFP) control embryos confirmed that it localized in the tegmentum, diencephalon, hindbrain and lateral line ganglia, as previously reported [47] (Fig. 3a). Of note, the $\mathrm{Tg}$ (neurod1:eGFP) exposed to syn3 KD showed a decreased eGFP signal in telencephalic and diencephalic regions where the dopaminergic neurons localize (Fig. 3a). The decrease of eGFP-positive signal in the head of the Tg(neurod1:GFP) zebrafish embryos injected with Syn II-MO (Online Resource 1) vs those inoculated with ST-MO (Online Resource 2) was also corroborated by light-sheet microscopybased 3D visualization.

Since dopaminergic projections from the brain promote motor neuron generation in the developing zebrafish [50], and we detected a decrease of both brain and motor neurons development in the larvae exposed to syn3 KD, we also performed time-lapse-based light-sheet microscopy acquisition of whole Syn III-MO vs ST-MO-injected $\mathrm{Tg}$ (neurod1:eGFP) larvae from 19 to $24 \mathrm{hpf}$. This allowed to appreciate that the neurodevelopmental decrease observed in the embryos exposed to syn3 KD involved both head and trunk neurons (Online Resource 3, 4).

Finally, as the Syn III-MO embryos appeared to exhibit hyperactive movements, we evaluated whether syn3 KD-induced reduction of neuronal development could impact on zebrafish motility by analyzing touch-evoked swimming at $72 \mathrm{hpf}$. The percentage of Syn III-MO-injected Tg(neurod1:eGFP) embryos exhibiting reduced swimming distance progressively increased within the interval between $5-10 \mathrm{~mm}$ and > $20 \mathrm{~mm}$ (Fig. 3b,c). Moreover, at 2, 3 and $4 \mathrm{dpf}$, we also analyzed the corkscrew swimming, a spiral swimming with increased speed in uncoordinated direction. A 12\%, 16\% and $21 \%$ increase in the Syn IIF- 
MO-injected Tg(neurod1:eGFP) embryos presenting corkscrew movements with respect to ST-MO-injected littermates was observed at 2, 3 and $4 \mathrm{dpf}$, respectively (Fig. 3d). The percentage of embryos with flip movements was also significantly increased after Syn IIIMO injection at $21 \mathrm{hpf}$ (Fig. 3e).

The neurodevelopmental decrease associated with zebrafish syn3 KD is rescued by rat Syn III mRNA expression

By analyzing sequence homology between the polypeptide sequences of zebrafish syn3 and its human, rat and mouse orthologues (Online resource 5a), we found that the percent identity in amino acid sequence between Danio Rerio and either Mus Musculus or Rattus Norvegicus was $66 \%$, while it raised to $67 \%$ when compared to the Homo Sapiens form. As expected, the sequence homology between mammals was higher, reaching $92 \%$ between rat or mouse and human and $98 \%$ between rat and mouse (Online resource $5 \mathrm{~b}$ ). A highly conserved synteny between the region surrounding human SYN3 on chromosome 22, mouse chromosome 10 and the region surrounding Danio Rerio homologue on chromosomes 4 was detected (green boxes, Online resource $5 c$ ). The high degree of sequence similarity and the strong synteny could be explained by the presence of positive evolutionary pressure on the Syn III gene, strongly suggesting a conservation of protein function across vertebrate evolution, as previously reported [37].

To corroborate the specificity of syn3 KD on neuronal development and assess whether the Syn III regions controlling neuronal development are conserved in mammals, we investigated the ability of rat Syn III mRNA to rescue the abnormal neuronal phenotype in the zebrafish $\mathrm{Tg}$ (neurod1:eGFP) embryos injected with Syn III-MO. To this purpose, a pCS2+ plasmid transducing rat Syn III mRNA was injected at the dose of $100 \mathrm{pg} / \mathrm{embryo}$ in $\mathrm{Tg}$ (neurod1:eGFP). The injection of the rat Syn III mRNA expression plasmid redeemed the morphological changes in the phenotype of Syn III-MO-Tg(neurod1:eGFP)-injected embryos (Fig. 4a) and rescued the significant reduction of full length zebrafish Syn III protein levels observed in the Syn III-MO Tg(neurod1:EGFP)-injected embryos at 48 hpf (Fig. 4b,c). Consistently, the rat Syn III mRNA expression plasmid also rescued the reduction in brain development observed in the SynII-MO injected $\mathrm{Tg}$ (neurod1:eGFP) embryos at $48 \mathrm{hpf}$ (Fig. 4d,f).

By TH immunostaining in the $\mathrm{Tg}$ (neurod1:eGFP) larvae at $48 \mathrm{hpf}$, we found that rat Syn III-mRNA expression rescued the significant reduction of $\mathrm{TH}$-positive area observed in the ventral telencephalon and dorsal diencephalon of Syn III-MO-injected Tg(neurod1:eGFP) embryos, with respect to ST-MOinjected littermates (Fig. 4d,g).

Since light-sheet microscopy-based time-lapse imaging suggested that Syn III-MO-injected $\mathrm{Tg}$ (neurod1:eGFP) embryos also exhibited a reduced motor neuron development, we assessed whether this could associate with a reduction in axonal length in the spinal cord, whose development depends on brain DA production [50]. We found a significant decrease in the length of the axons innervating the 5th 16th somite in the $\mathrm{Tg}$ (neurod1:eGFP) embryos injected with Syn III-MO, when compared to their littermates with ST-MO inoculations (Fig. 4e,h), that was rescued by the injection of rat Syn III mRNA expression plasmid (Fig. 4e,h). 
The recovery of brain TH immunopositivity and eGFP-positive neurons as well as of spinal cord axonal length observed upon rat Syn III mRNA expression in zebrafish supports that fishes and mammals Syn III share the same neurodevelopmental regulatory sequences.

\section{Syn III affects the development of mouse SN neurons in vivo}

The impact of Syn III during neurodevelopment was then assessed by using Syn III ko mice [3, 51]. In particular, we evaluated whether newborn, 2- or 10-month-old Syn III ko mice exhibited signs of nigrostriatal mDN developmental impairment.

First, the absence of Syn III expression in the $\mathrm{SN}$ and striatum was confirmed by western blot analysis (Online resource 6). Interestingly, this evidenced an age-dependent decrease of Syn III levels in the wt mice (Online resource 6). In parallel, since Syns are known to act in heterodimeric complexes and exhibit an elevated sequence similarity [5,52], we checked whether the deficiency of Syn III could induce homeostatic compensatory changes in either Syn II or Syn I expression. We found that, though Syn II levels were comparable in wt and Syn III ko mice at the various time points analyzed, Syn I levels resulted significantly reduced in the midbrain and striatum of Syn III ko mice at 10 months of age (Online resource 6). This suggests that the absence of Syn III does not impact on Syn I expression during brain development but can affect it in the long term likely as a compensatory effect in light of the elevated sequence homology shared by these Syns $[5,52]$.

To evaluate whether the absence of Syn III influences the development of dopaminergic neurons, we assessed the percentage changes in the number of TH-positive cells in the $\mathrm{SN}$ and in the TH-positive dendritic projections of the prin newborn, 2 and 10 month-old wt and Syn III ko mice (Fig. 5a) [24]. By stereology, we found that newborn Syn III ko mice exhibited a significant $50 \%$ and $52 \%$ reduction in the number of SN TH-positive cells and prTH-positive processes vs wt mice, respectively. We also performed two-photon-based acquisition of whole SN from newborn mouse brains subjected to X-clarity-based clearing and deep-tissue TH fluorescent immunolabeling. Of note, the 3D reconstruction of tile-scan acquisitions of TH-positive cells confirmed the reduction of SN mDN development in the newborn Syn III ko (Online resource 7) vs wt mice (Online resource 8) that was previously observed by brightfield microscopy.

Interestingly, while the reduction of SN neurons was recovered at 2 and 10 months of age, the decrease of pr TH-positive processes was still present at 2 months of age, but disappeared in older mice (Fig. 5a).

We then observed that the reduction of SN mDN cells in Syn III ko newborn mice when compared to wt animals was reflected by a $70 \%$ decrease in striatal TH-positive projections (Fig. $5 \mathrm{~b}$ ). In spite of this, the Syn III ko mice no more exhibited decreases in TH-positive projections in the striatum at 2 and 10 months of age (Fig. 5b). 
These immunohistochemical findings collimated with the western blot-based evaluation of TH levels in the midbrain (Fig. 5c) and striatum (Fig. 5d).

Collectively, these observations suggest that the absence of Syn III influences the earlier stages of SN $\mathrm{mDN}$ development with a greater impact on the dendritic arborizations of these cells.

We then assessed whether the decrease of $p r \mathrm{TH}$-positive arborization could influence the motor abilities of Syn III ko mice by using the rotarod and pole tests (Fig. 6a,b). To assess the acquisition of skilled behavior minimizing the learning feature in the rotarod and pole tests, wt and Syn III ko mice at 2 or 10 months of age were employed in training trials on the first day and both the best trial and mean trial of the second day were evaluated.

No differences between the motility of wt and Syn III ko animals was detected in either the rotarod or the pole test at 2 or 10 months of age (Fig. $6 a, b$ ), suggesting that the reduced prarborization in 2-month-old Syn III ko mice did not significantly influence their basal motor activity or coordination.

Early in vitro development of mouse primary $\mathrm{mDN}$ is altered in the absence of Syn III

Midbrain neurons were dissected from 13 days wt and Syn III ko embryos and cultured for 1,3 or 10 div as previously described [7]. The dendritic branching of TH-positive neurons was evaluated by using a conventional Sholl analysis [53], showing a significant decrease in the number of intersections between neuronal dendritic projections and concentric circles in Syn III ko neurons when compared with wt at div 1 (Fig. 7a, Online resource 9a). These differences were abated at 3 and 10 div, when the number of intersections of TH-immunopositive neurons from Syn III ko mice were comparable to that of wt animals (Fig. 7a). Moreover, we found that Syn III ko neurons exhibited a significant decrease in the number of branches at div 1 and 3 (Fig. 7b), as well as in the soma area at div 1 (Fig. 7c). These observations further corroborate that Syn III can affect the very early stages of mDN maturation.

We then evaluated whether the observed early deficits in $\mathrm{mDN}$ development at div 1 can be restored by 24 $\mathrm{h}$ BDNF or DA treatment. Indeed, BDNF is required for the establishment of the proper number of dopaminergic neurons in the SN pars compacta [54], which were reduced in the Syn III ko newborn mice as explained above. Interestingly, following $10 \mathrm{ng} / \mathrm{ml}$ BDNF treatment, Syn III ko TH-positive primary midbrain neurons exhibited a number of intersections, branches and a mean soma area comparable to those of wt cells (Fig. 7d-f, Online resource 9b). This notwithstanding, BDNF treatment did not influence these parameters in the wt mice (Fig. 7d-f), thus supporting the possibility that the delayed developmental pattern of Syn III deficient mDN neurons confers an improved capability to respond to BDNF. This observation supported the occurrence of BDNF receptors hypersensitivity in the primary mDN from Syn III ko mice, a phenomenon which could result from a lower BDNF production [55]. Consistently, by probing the levels of prepro-BDNF and mature BDNF in the midbrain of newborn Syn III ko and wt mice, we found a significant reduction of both prepro-BDNF and mature BDNF in the Syn III ko newborn mice (Online resource 6i), supporting that Syn III deficiency may impact on midbrain BDNF production. 
Differently to what observed after BDNF treatment, $0.1 \mu \mathrm{M}$ DA treatment did not influence the number of intersections, branches or mean soma area of either Syn III ko or wt mouse TH-positive primary mDN (Fig. 7g-l, Online resource 9c), in line with evidence supporting that mDN do not express mature and functional DA autoreceptors at $1 \operatorname{div}[56,57]$.

It has been shown that the Syn III-mediated promotion of primary cortical neurons maturation in the early stages of development (3 div) are improved upon its phosphorylation by Cdk5 [4], which is also involved in BDNF-induced dendritic growth [58]. We thus evaluated whether the neuronal arborization of Syn III ko or wt primary $\mathrm{mDN}$ was differentially affected by the treatment with the Cdk5 inhibitor roscovitine. To this purpose, mDN from either wt or Syn III ko mice were treated with $1 \mu \mathrm{M}$ roscovitine for $24 \mathrm{~h}$ at div 3 . Roscovitine significantly reduced the number of intersections without affecting the number of branches or mean soma area of primary TH-positive mDN from wt mice, but its effect was occluded in Syn III ko mice (Fig. 7j-I, Online resource 9d), supporting that Cdk5-dependent control of $\mathrm{mDN}$ development is disrupted in the absence of Syn III.

\section{Early maturation of human iPSCs-derived DA neurons is altered by Syn III gene silencing}

Finally, we evaluated whether the development of human DA neurons differentiated from iPSCs could be altered by Syn III gene silencing. To this aim, iPSCs from two healthy subjects [33, 34], referred to as CTRL-1 and CTRL-2, were used. Human iPSCs were infected with an AAV expressing either shRNA silencing SYN3 (AAV-shSynIII) or non-silencing RNA sequences (AAV-shNSC). Then, by using a wellestablished protocol for the differentiation of iPSCs into TH/DA transporter (DAT)-positive DA neurons, iPSCs were differentiated until day 50 into a neuronal population enriched in DA neurons [36, 59]. Each line was individually analyzed by immunocytochemistry at three different time points (div 25 , div 40 , div 50) (Fig. 8, Online resource 10a,b). Syn III gene silencing was maintained throughout the differentiation process, as confirmed by western blot analysis (Online resource 10c-f). The morphology of these neurons was analyzed by immunocytochemistry and computer-assisted morphometry using the average maximal length of the primary dendrite (from the soma to the first ramification), the number of dendrites and the soma area [34]. At 25 div, TH-positive neurons from AAV-shSynlll exhibited reduced primary dendrite length, dendritic arborization and decreased soma area as compared to both AAV-shNSC and noninfected TH-positive neurons. These differences were abated at day 40 and day 50 , when the morphology of TH-positive neurons from AAV-shSynIII were comparable to that of both AAV-shNSC and non-infected TH-positive neurons (Fig. 8). These findings support that Syn III also plays a key role in controlling the very early steps of human DA neuron development.

\section{Discussion}

Syn III is known to be implicated in the control of axonal growth as well as in the migration, orientation, differentiation and survival of neuronal progenitors of cortical and hippocampal neurons $[3,4,60,61]$. Its expression in the very early developmental stages in vertebrate and invertebrates organisms sounds in 
line with this function [5]. Moreover, studies linking Syn III polymorphisms to the onset and response to therapy in ADHD, a neurodevelopmental disorder characterized by alterations of both the mesocorticolimbic and nigrostriatal dopaminergic pathway, demanded a better characterization of the role of Syn III in mDN development $[15,16,22]$.

The present results support that Syn III controls the very early stages of mDN development and that this function has been preserved in different species. In particular, we found that in zebrafish, syn3 KD impairs the development of brain neurons, including TH-positive neurons. Consistently, the syn3 KD zebrafish larvae exhibited decreased expression of $n g n 1$, Islet-1 and gfap in the developing nervous system as well as motor alterations characterized by a progressive reduction of overall motility paralleled by an increase in tail flip and corkscrew movements, that are reminiscent of an ADHD-like phenotype. Strikingly, the neurodevelopmental reduction associated with syn3 KD in zebrafish was rescued by the expression of rat Syn III mRNA, supporting that the relevant Syn III protein portions controlling mDN development have been phylogenetically conserved from fishes to mammals.

Of note, the chemogenetic ablation of dopaminergic neurons in zebrafish larvae reproduced a behavioral phenotype that looks very similar to that observed in the Syn III KD morphants [62], including a reduction of the overall swimming distance and increase in the head to tail angle coupled with a decrease in head to tail bend amplitude which is supportive of the presence of corkscrew and tail flip movements. This evidence, reinforces that the Syn III deletion-related dopaminergic neurons development may be at the basis of the motility impairment observed in the Syn III KD larvae. Interestingly, we also observed that the $\mathrm{mDN}$ developmental deficits observed in the syn3 KD zebrafish larvae were paralleled by a reduction in the development of spinal cord motor neurons. Although we cannot exclude that this can be directly ascribed to Syn III gene KD, the fact that spinal cord motor neurons development is stimulated by brain DA [50] suggests that the reduced mDN development could be at the basis of this phenomenon.

It is worth to take into consideration that several ADHD causal genes are highly expressed in both fetal astrocytes and neurons [63]. Moreover, astrocyte alterations can underlie ADHD manifestations, while proper astrocyte activity is relevant for dopaminergic neurons function [64-67]. Therefore, the here reported reduction of gfap expression in syn3 KD zebrafish embryos, in addition to reflecting an overall reduction of the expression of $g$ fap in the common neuronal/astrocyte precursors, suggests that SYN3 polymorphisms may also lead to a decrease in astrocytes development, that could potentially further contribute to alterations in DA-evoked synaptic regulation and ADHD onset.

By studying primary midbrain neuronal cultures and brains from newborn, 2 and 10 month-old Syn III ko or C57BL/6 J wt mice, we observed that, in the very early phases of development, Syn III deficiency reduces both TH-positive mDN number as well as their striatal axonal projections and prdendritic processes. However, at 2 months of age, the reduction in the number of $\mathrm{TH}$-positive neurons in the SN and striatal fibers density of Syn III ko mice was recovered, though these animals still exhibited a decrease in the TH-positive prprojections, which in turn was no more detectable at 10 months of age. Interestingly, the decrease of SN dopaminergic neurons pr projections at 2 months of age was not 
associated with motility deficits or altered motor coordination. This is in line with findings showing that the Syn III ko mice do not exhibit overt signs of sensory and motor functions deficits [1]. Nevertheless, they manifest deficits in object recognition, social transmission of food preference without anxiety or depressive-like behaviors [1]. In line with the fact that Syn III deficient mice manifest a reduction of cocaine-induced facilitation of DA release [6], we observed that they do not even present a locomotor response following acute administration of cocaine [12]. In addition, despite the aged Syn III ko mice exhibit a full recovery of nigrostriatal dopaminergic neurons number and arborizations, we found that differently to C56BL/6J mice, they do not exhibit a motility improvement following the acute i.p. administration of $\mathrm{MPH}$, consistently with findings showing that the action of this drug can be mediated by Syn III [12, 13].

It has been previously shown that hippocampal neurons from Syn III ko mice display delayed axonal growth, as well as improved size of synaptic vesicles recycling pool and decreased inhibitory postsynaptic currents (IPSC) amplitude and synaptic depression, but in the absence of morphological alterations in the density or distribution of synaptic vesicles [51], that is also preserved in striatal dopaminergic terminals [24]. These animals also show enhanced electrical stimulation-evoked DA release in the striatum, thus supporting that Syn III acts as a negative regulator of dopaminergic neurotransmission [6]. Since this does not appear sufficient to affect their motor functions, it is likely that these mice exhibit compensatory alterations in synaptic vesicle turnover or other synaptic homeostatic changes at striatal dopaminergic terminals. Worth of note, the reduction of $p r$ dendritic arborizations observed in the present study may very well lead to deficits in the establishment of input connections in this area. Indeed, the activity of $\mathrm{SN}$ dopaminergic neurons is physiologically inhibited by $\operatorname{pr}^{-}$ aminobutirric acid (GABA) afferents [68-70]. In particular, the activity of GABAergic afferents can finely control the timing of phasic DA signals in the striatum [71]. On this line, it has been found that mice deficient of Tal1 gene, which encodes a transcription factor that is crucial for promoting GABAergic differentiation in midbrain dopaminergic nuclei, exhibit ADHD-like behavioral features including impulsivity, hypersensitivity to reward, learning deficits, defects in the habituation to a novel environment and an hyperactive behavior rescued by increased DA signaling [72]. When coupled to our results, this evidence supports that alterations of pr GABAergic inhibitory afferents controlling SN dopaminergic neurons may also participate in the onset of ADHD phenotype. We can thus hypothesize that although the early decrease in dopaminergic neurons development associated with Syn III deletion appears to be compensated during animal growth, it is feasible that specific deficits in the $p r$ dendritic arborization can compromise the proper establishment of GABAergic afferent network connections up to adulthood. This could contribute to the onset of alterations in the proper establishment of basal ganglia circuits, in turn leading to ADHD manifestation. Further investigations in the Syn III ko mice will be crucial to test this hypothesis.

Remarkably, we also observed that Syn III deficient primary mDN manifested early developmental alterations that were accompanied by a significant improved ability to respond to BDNF-mediated stimulation of dendritic branching and soma area, and by the disruption of Cdk5-mediated control of early dendritic elongation, in line with previous studies on primary cortical neurons [4]. The BDNF 
hypersensitivity and Cdk5-signaling disruption in Syn III ko animals may support that Syn III deletion could reduce BDNF production. Consistently, we found a significant decrease of both prepro-BDNF and mature BDNF in midbrain protein extracts from Syn III ko newborn mice. These features are reminiscent of studies on dopaminergic neurons derived from dental pulp stem cells from children with ADHD, which exhibit impairments in neurite development, but respond to BDNF treatment [73]. Our observations thus support the idea that Syn III regulates the ability of $\mathrm{mDN}$ neurons to properly respond to BDNF stimulation by acting upstream of BDNF production, in contrast with findings on primary cortical neurons, where Syns have been found to act downstream of BDNF signaling to regulate axonal growth [74].

BDNF plays a fundamental role in the establishment of the correct number of SN neurons, as well in the development of their proximal dendrites [54, 75]. Taking into account that BDNF-stimulated dendritic development is mediated by Cdk5 [58], the absence of roscovitine-mediated Cdk5 inhibition in Syn ko mDN appears fully in line with a Syn III-deficiency-related loss of BDNF stimulation. Further studies will be needed to finely characterize the molecular underpinning of Syn III-dependent control of early mDN development. However, when coupled to the present results, evidence showing that ADHD subjects exhibit reduced BDNF serum levels [76] suggests the existence of a possible link between Syn III polymorphisms and BDNF signaling alterations in the pathophysiology of this disorder. This is further reinforced by the fact that MPH, a drug which can bind to Syn III, has been found to improve BDNF levels in ADHD patients $[77,78]$ and even in the hippocampus of hypoxic-ischemic rats [79]. Moreover, MPH can promote neurogenesis in the hippocampus [80], an area where Syn III is particularly abundant in the adult brain [81]. It may be thus feasible that Syn III polymorphisms may affect MPH therapeutic response of ADHD patients by altering MPH-stimulated BDNF production.

In relation with the results supporting a reduction of BDNF production in Syn III ko mice it is also relevant to consider that BDNF expression has been found to be regulated by neuronal activity [82-85]. This supports the possibility that a Syn III-deletion-related reduction of neuronal activity could also be at the basis of the observed Syn III ko-related BDNF decrease. However, a pivotal study on primary hippocampal neurons showed that that Syn III plays a key role in early axon development well before the first synapses are established [51]. The same authors also demonstrated although IPSCs at GABAergic inhibitory synapses are greatly reduced, there is no difference in the quantal content of excitatory post-synaptic currents (EPSC) or in the number of vesicles that fuse per action potential between Syn III ko and wt mice following low-frequency stimulation [51]. However, the increase of synaptic vesicle pools recycling observed in Syn III ko neurons could contribute to the slower synaptic depression induced by protracted neuronal activity, that is supported by the milder decrease in the amplitudes of evoked EPSCs following prolonged trains of action potentials [51]. Therefore, although we cannot fully rule out the possibility that that a decrease of synaptic activity related to the Syn III absence may also reduce BDNF expression, these observations suggest that the impact of Syn III deletion on neuronal activity may not be sufficient to sustain a reduction of BDNF production at very early developmental stages. This is further supported by the fact that although Syn III ko mouse primary dopaminergic neurons at 1 div exhibited an improved BDNF response that appears indicative of receptors hypersensitivity in response to BDNF decrease, the rodent primary neurons in culture do not display mature synapses till 7 div [86-89]. 
Finally, we also showed that the early neurodevelopmental mDN decrease induced by Syn III deficiency can be even observed in dopaminergic neurons produced from human iPSCs exposed to AAV-mediated Syn III gene silencing, which exhibited a significant reduction of primary dendrites length and numbers or soma size at 25 div. In line with the observations on Syn III ko mice, this was fully rescued at 40 div.

Collectively, our results indicate that Syn III is a key regulator of the early stages of mDN development that in mammals is related to BDNF/Cdk5 signaling. These findings suggest that the Syn III polymorphisms associated with ADHD could underlie early neurodevelopmental morphological dopaminergic alterations. Although these may be slowly recovered along aging, their impact on basal ganglia circuitry homeostasis may persist up to adulthood flowing into ADHD manifestation.

\section{Declarations}

\section{Funding}

This work was supported by the University of Brescia local funding Ex 60 \% 2017-2020 to AB and DZ, the Italian MIUR PRIN 2017-1065, the MIUR PNR 2015-2020 PerMedNet and the Michael J. Fox Foundation for Parkinson's Research, NY, USA (Target Advancement Program, grant ID \#10742.01) to AB.

\section{Competing Interests}

The authors declare that no conflict of interest exists.

\section{Acknowledgements}

We are grateful to Dr. Luca Mignani for technical assistance during light sheet microscopy acquisitions.

\section{Author Contributions}

Conceptualization: AB, DZ, GF, FL, MM

Methodology: AB, DZ, GF, FL, AM, FB, LLV, FO

Investigation: GF, FL, AM, FB, LLV

Visualization: $A B, D Z, C M, F B$

Supervision: $A B, D Z, M M, C M, M P$

Writing-original draft: AB, DZ, GF, FL, FB

Writing-review \& editing: AB, DZ, GF, FL, FB

\section{Data and materials availability}


The authors confirm that the data supporting the findings of this study are available within the article and its supplementary materials. The raw data that support the findings of this study are available from the corresponding authors, $A B$ and $D Z$, upon reasonable request.

\section{Ethics approval}

This study was performed in accordance to the Directive 2010/63/EU of the European Parliament and of the Council of 22 September 2010 on the protection of animals used. All experimental and surgical procedures conformed to the National Research Guide for the Care and Use of Laboratory Animals were approved by the Animal Research Committees of the University of Brescia (Protocol Permit 719/2015$\mathrm{PR})$.

\section{References}

1. Porton B, Rodriguiz RM, Phillips LE, Gilbert JWt, Feng J, Greengard P, et al. Mice lacking synapsin III show abnormalities in explicit memory and conditioned fear. Genes, brain, and behavior. 2010;9(3):25768.

2. Kao HT, Porton B, Czernik AJ, Feng J, Yiu G, Haring M, et al. A third member of the synapsin gene family. Proceedings of the National Academy of Sciences of the United States of America. 1998;95(8):4667-72.

3. Perlini LE, Szczurkowska J, Ballif BA, Piccini A, Sacchetti S, Giovedi S, et al. Synapsin III acts downstream of semaphorin $3 \mathrm{~A} / \mathrm{CDK} 5$ signaling to regulate radial migration and orientation of pyramidal neurons in vivo. Cell reports. 2015;11(2):234-48.

4. Piccini A, Perlini LE, Cancedda L, Benfenati F, Giovedi S. Phosphorylation by PKA and Cdk5 Mediates the Early Effects of Synapsin III in Neuronal Morphological Maturation. The Journal of neuroscience : the official journal of the Society for Neuroscience. 2015;35(38):13148-59.

5. Longhena F, Faustini G, Brembati V, Pizzi M, Benfenati F, Bellucci A. An updated reappraisal of synapsins: structure, function and role in neurological and psychiatric disorders. Neuroscience and biobehavioral reviews. 2021;130:33-60.

6. Kile BM, Guillot TS, Venton BJ, Wetsel WC, Augustine GJ, Wightman RM. Synapsins differentially control dopamine and serotonin release. The Journal of neuroscience : the official journal of the Society for Neuroscience. 2010;30(29):9762-70.

7. Zaltieri M, Grigoletto J, Longhena F, Navarria L, Favero G, Castrezzati S, et al. alpha-synuclein and synapsin III cooperatively regulate synaptic function in dopamine neurons. J Cell Sci. 2015;128(13):223143. 
8. Porton B, Wetsel WC. Reduction of synapsin III in the prefrontal cortex of individuals with schizophrenia. Schizophrenia research. 2007;94(1-3):366-70.

9. Kenar AN, Edgunlu T, Herken H, Erdal ME. Association of synapsin III gene with adult attention deficit hyperactivity disorder. DNA Cell Biol. 2013;32(8):430-4.

10. Longhena F, Faustini G, Varanita T, Zaltieri M, Porrini V, Tessari I, et al. Synapsin III is a key component of alpha-synuclein fibrils in Lewy bodies of PD brains. Brain Pathol. 2018;28(6):875-88.

11. Basay O, Kabukcu Basay B, Alacam H, Ozturk O, Buber A, Gorucu Yilmaz S, et al. The impact of synapsin III gene on the neurometabolite level alterations after single-dose methylphenidate in attentiondeficit hyperactivity disorder patients. Neuropsychiatr Dis Treat. 2016;12:1141-9.

12. Faustini G, Longhena F, Bruno A, Bono F, Grigoletto J, La Via L, et al. Alpha-synuclein/synapsin III pathological interplay boosts the motor response to methylphenidate. Neurobiology of disease. 2020;138:104789.

13. Casiraghi A, Longhena F, Straniero V, Faustini G, Newman AH, Bellucci A, et al. Design and Synthesis of Fluorescent Methylphenidate Analogues for a FRET-Based Assay of Synapsin III Binding. ChemMedChem. 2020;15(14):1330-7.

14. Faraone SV, Asherson P, Banaschewski T, Biederman J, Buitelaar JK, Ramos-Quiroga JA, et al. Attention-deficit/hyperactivity disorder. Nat Rev Dis Primers. 2015;1:15020.

15. Forssberg H, Fernell E, Waters S, Waters N, Tedroff J. Altered pattern of brain dopamine synthesis in male adolescents with attention deficit hyperactivity disorder. Behav Brain Funct. 2006;2:40.

16. del Campo N, Fryer TD, Hong YT, Smith R, Brichard L, Acosta-Cabronero J, et al. A positron emission tomography study of nigro-striatal dopaminergic mechanisms underlying attention: implications for ADHD and its treatment. Brain. 2013;136(Pt 11):3252-70.

17. Matsuda W, Furuta T, Nakamura KC, Hioki H, Fujiyama F, Arai R, et al. Single nigrostriatal dopaminergic neurons form widely spread and highly dense axonal arborizations in the neostriatum. The Journal of neuroscience : the official journal of the Society for Neuroscience. 2009;29(2):444-53.

18. Lerner TN, Shilyansky C, Davidson TJ, Evans KE, Beier KT, Zalocusky KA, et al. Intact-Brain Analyses Reveal Distinct Information Carried by SNc Dopamine Subcircuits. Cell. 2015;162(3):635-47.

19. Menegas W, Bergan JF, Ogawa SK, Isogai Y, Umadevi Venkataraju K, Osten P, et al. Dopamine neurons projecting to the posterior striatum form an anatomically distinct subclass. Elife. 2015;4:e10032.

20. Beier KT, Steinberg EE, DeLoach KE, Xie S, Miyamichi K, Schwarz L, et al. Circuit Architecture of VTA Dopamine Neurons Revealed by Systematic Input-Output Mapping. Cell. 2015;162(3):622-34. 
21. Bissonette GB, Roesch MR. Development and function of the midbrain dopamine system: what we know and what we need to. Genes Brain Behav. 2016;15(1):62-73.

22. Jucaite A, Fernell E, Halldin C, Forssberg H, Farde L. Reduced midbrain dopamine transporter binding in male adolescents with attention-deficit/hyperactivity disorder: association between striatal dopamine markers and motor hyperactivity. Biological psychiatry. 2005;57(3):229-38.

23. Kimmel CB, Ballard WW, Kimmel SR, Ullmann B, Schilling TF. Stages of embryonic development of the zebrafish. Developmental dynamics : an official publication of the American Association of Anatomists. 1995;203(3):253-310.

24. Faustini G, Longhena F, Varanita T, Bubacco L, Pizzi M, Missale C, et al. Synapsin III deficiency hampers alpha-synuclein aggregation, striatal synaptic damage and nigral cell loss in an AAV-based mouse model of Parkinson's disease. Acta Neuropathol. 2018;136(4):621-39.

25. Sievers F, Wilm A, Dineen D, Gibson TJ, Karplus K, Li W, et al. Fast, scalable generation of high-quality protein multiple sequence alignments using Clustal Omega. Mol Syst Biol. 2011;7:539.

26. Thisse C, Thisse B. High-resolution in situ hybridization to whole-mount zebrafish embryos. Nature protocols. 2008;3(1):59-69.

27. Dobrzycki T, Krecsmarik M, Monteiro R. Genotyping and Quantification of In Situ Hybridization Staining in Zebrafish. J Vis Exp. 2020(155).

28. Perkins BD, Nicholas CS, Baye LM, Link BA, Dowling JE. dazed gene is necessary for late cell type development and retinal cell maintenance in the zebrafish retina. Developmental dynamics : an official publication of the American Association of Anatomists. 2005;233(2):680-94.

29. Robinson KJ, Yuan KC, Don EK, Hogan AL, Winnick CG, Tym MC, et al. Motor Neuron Abnormalities Correlate with Impaired Movement in Zebrafish that Express Mutant Superoxide Dismutase 1. Zebrafish. 2019;16(1):8-14.

30. Benedetti L, Ghilardi A, Rottoli E, De Maglie M, Prosperi L, Perego C, et al. INaP selective inhibition reverts precocious inter- and motorneurons hyperexcitability in the Sod1-G93R zebrafish ALS model. Sci Rep. 2016;6:24515.

31. Goody MF, Kelly MW, Reynolds CJ, Khalil A, Crawford BD, Henry CA. NAD+ biosynthesis ameliorates a zebrafish model of muscular dystrophy. PLoS biology. 2012;10(10):e1001409.

32. Bellucci A, Collo G, Sarnico I, Battistin L, Missale C, Spano P. Alpha-synuclein aggregation and cell death triggered by energy deprivation and dopamine overload are counteracted by D2/D3 receptor activation. Journal of neurochemistry. 2008;106(2):560-77. 
33. Bono F, Mutti V, Piovani G, Minelli A, Mingardi J, Guglielmi A, et al. Establishment and characterization of induced pluripotent stem cell (iPSCs) line UNIBSi014-A from a healthy female donor. Stem Cell Res. 2021;51:102216.

34. Bono F, Savoia P, Guglielmi A, Gennarelli M, Piovani G, Sigala S, et al. Role of Dopamine D2/D3 Receptors in Development, Plasticity, and Neuroprotection in Human iPSC-Derived Midbrain Dopaminergic Neurons. Mol Neurobiol. 2018;55(2):1054-67.

35. Kriks S, Shim JW, Piao J, Ganat YM, Wakeman DR, Xie Z, et al. Dopamine neurons derived from human ES cells efficiently engraft in animal models of Parkinson's disease. Nature. 2011;480(7378):54751.

36. Bono F, Mutti V, Savoia P, Barbon A, Bellucci A, Missale C, et al. Nicotine prevents alpha-synuclein accumulation in mouse and human iPSC-derived dopaminergic neurons through activation of the dopamine D3- acetylcholine nicotinic receptor heteromer. Neurobiol Dis. 2019;129:1-12.

37. Garbarino G, Costa S, Pestarino M, Candiani S. Differential expression of synapsin genes during early zebrafish development. Neuroscience. 2014;280:351-67.

38. Schweitzer J, Lohr H, Filippi A, Driever W. Dopaminergic and noradrenergic circuit development in zebrafish. Dev Neurobiol. 2012;72(3):256-68.

39. Du Y, Guo Q, Shan M, Wu Y, Huang S, Zhao H, et al. Spatial and Temporal Distribution of Dopaminergic Neurons during Development in Zebrafish. Front Neuroanat. 2016;10:115.

40. Panula P, Chen YC, Priyadarshini M, Kudo H, Semenova S, Sundvik M, et al. The comparative neuroanatomy and neurochemistry of zebrafish CNS systems of relevance to human neuropsychiatric diseases. Neurobiol Dis. 2010;40(1):46-57.

41. Hua K, Ekker M. Chapter 22 - Life, death, and regeneration of zebrafish dopaminergic neurons. Behavioral and Neural Genetics of Zebrafish. 2020:363-76.

42. Mueller T, Wullimann MF. Expression domains of neuroD (nrd) in the early postembryonic zebrafish brain. Brain research bulletin. 2002;57(3-4):377-9.

43. Li S, Yin M, Liu S, Chen Y, Yin Y, Liu T, et al. Expression of ventral diencephalon-enriched genes in zebrafish. Developmental dynamics : an official publication of the American Association of Anatomists. 2010;239(12):3368-79.

44. Maienschein V, Marxen M, Volknandt W, Zimmermann H. A plethora of presynaptic proteins associated with ATP-storing organelles in cultured astrocytes. Glia. 1999;26(3):233-44.

45. Wang S, Cesca F, Loers G, Schweizer M, Buck F, Benfenati F, et al. Synapsin I is an oligomannosecarrying glycoprotein, acts as an oligomannose-binding lectin, and promotes neurite outgrowth and 
neuronal survival when released via glia-derived exosomes. The Journal of neuroscience : the official journal of the Society for Neuroscience. 2011;31(20):7275-90.

46. Bernardos RL, Raymond PA. GFAP transgenic zebrafish. Gene expression patterns : GEP. 2006;6(8):1007-13.

47. Thomas JL, Ochocinska MJ, Hitchcock PF, Thummel R. Using the Tg(nrd:egfp)/albino zebrafish line to characterize in vivo expression of neurod. PloS one. 2012;7(1):e29128.

48. Blader P, Plessy C, Strahle U. Multiple regulatory elements with spatially and temporally distinct activities control neurogenin 1 expression in primary neurons of the zebrafish embryo. Mech Dev. 2003;120(2):211-8.

49. Satou C, Kimura Y, Hirata H, Suster ML, Kawakami K, Higashijima S. Transgenic tools to characterize neuronal properties of discrete populations of zebrafish neurons. Development. 2013;140(18):3927-31.

50. Reimer MM, Norris A, Ohnmacht J, Patani R, Zhong Z, Dias TB, et al. Dopamine from the brain promotes spinal motor neuron generation during development and adult regeneration. Dev Cell. 2013;25(5):478-91.

51. Feng J, Chi P, Blanpied TA, Xu Y, Magarinos AM, Ferreira A, et al. Regulation of neurotransmitter release by synapsin III. J Neurosci. 2002;22(11):4372-80.

52. Cesca F, Baldelli P, Valtorta F, Benfenati F. The synapsins: key actors of synapse function and plasticity. Prog Neurobiol. 2010;91(4):313-48.

53. Longhena F, Zaltieri M, Grigoletto J, Faustini G, La Via L, Ghidoni R, et al. Depletion of Progranulin Reduces GluN2B-Containing NMDA Receptor Density, Tau Phosphorylation, and Dendritic Arborization in Mouse Primary Cortical Neurons. J Pharmacol Exp Ther. 2017;363(2):164-75.

54. Baquet ZC, Bickford PC, Jones KR. Brain-derived neurotrophic factor is required for the establishment of the proper number of dopaminergic neurons in the substantia nigra pars compacta. The Journal of neuroscience : the official journal of the Society for Neuroscience. 2005;25(26):6251-9.

55. Andreska T, Luningschror $P$, Sendtner $M$. Regulation of TrkB cell surface expression-a mechanism for modulation of neuronal responsiveness to brain-derived neurotrophic factor. Cell and tissue research. 2020;382(1):5-14.

56. Ford CP. The role of D2-autoreceptors in regulating dopamine neuron activity and transmission. Neuroscience. 2014;282:13-22.

57. Mishra A, Singh S, Shukla S. Physiological and Functional Basis of Dopamine Receptors and Their Role in Neurogenesis: Possible Implication for Parkinson's disease. J Exp Neurosci.

2018;12:1179069518779829. 
58. Cheung ZH, Chin WH, Chen Y, Ng YP, Ip NY. Cdk5 is involved in BDNF-stimulated dendritic growth in hippocampal neurons. PLoS biology. 2007;5(4):e63.

59. Bono F, Mutti V, Devoto P, Bolognin S, Schwamborn JC, Missale C, et al. Impaired dopamine D3 and nicotinic acetylcholine receptor membrane localization in iPSCs-derived dopaminergic neurons from two Parkinson's disease patients carrying the LRRK2 G2019S mutation. Neurobiology of aging. 2021;99:6578.

60. Kao HT, Li P, Chao HM, Janoschka S, Pham K, Feng J, et al. Early involvement of synapsin III in neural progenitor cell development in the adult hippocampus. The Journal of comparative neurology. 2008;507(6):1860-70.

61. Porton B, Wetsel WC, Kao HT. Synapsin III: role in neuronal plasticity and disease. Semin Cell Dev Biol. 2011;22(4):416-24.

62. Godoy R, Noble S, Yoon K, Anisman H, Ekker M. Chemogenetic ablation of dopaminergic neurons leads to transient locomotor impairments in zebrafish larvae. Journal of neurochemistry. 2015;135(2):249-60.

63. Fahira A, Li Z, Liu N, Shi Y. Prediction of causal genes and gene expression analysis of attentiondeficit hyperactivity disorder in the different brain region, a comprehensive integrative analysis of ADHD. Behavioural brain research. 2019;364:183-92.

64. Corkrum M, Covelo A, Lines J, Bellocchio L, Pisansky M, Loke K, et al. Dopamine-Evoked Synaptic Regulation in the Nucleus Accumbens Requires Astrocyte Activity. Neuron. 2020;105(6):1036-47 e5.

65. Todd RD, Botteron KN. Is attention-deficit/hyperactivity disorder an energy deficiency syndrome? Biological psychiatry. 2001;50(3):151-8.

66. Killeen PR, Russell VA, Sergeant JA. A behavioral neuroenergetics theory of ADHD. Neuroscience and biobehavioral reviews. 2013;37(4):625-57.

67. Sandau US, Alderman Z, Corfas G, Ojeda SR, Raber J. Astrocyte-specific disruption of SynCAM1 signaling results in ADHD-like behavioral manifestations. PloS one. 2012;7(4):e36424.

68. Tepper JM, Lee CR. GABAergic control of substantia nigra dopaminergic neurons. Progress in brain research. 2007;160:189-208.

69. Tepper JM, Martin LP, Anderson DR. GABAA receptor-mediated inhibition of rat substantia nigra dopaminergic neurons by pars reticulata projection neurons. The Journal of neuroscience : the official journal of the Society for Neuroscience. 1995;15(4):3092-103.

70. Henny P, Brown MT, Northrop A, Faunes M, Ungless MA, Magill PJ, et al. Structural correlates of heterogeneous in vivo activity of midbrain dopaminergic neurons. Nature neuroscience. 2012;15(4):613-9. 
71. Evans RC, Twedell EL, Zhu M, Ascencio J, Zhang R, Khaliq ZM. Functional Dissection of Basal Ganglia Inhibitory Inputs onto Substantia Nigra Dopaminergic Neurons. Cell reports. 2020;32(11):108156.

72. Morello F, Voikar V, Parkkinen P, Panhelainen A, Rosenholm M, Makkonen A, et al. ADHD-like behaviors caused by inactivation of a transcription factor controlling the balance of inhibitory and excitatory neuron development in the mouse anterior brainstem. Translational psychiatry. 2020;10(1):357.

73. Nguyen Nguyen HT, Kato H, Sato H, Yamaza H, Sakai Y, Ohga S, et al. Positive effect of exogenous brain-derived neurotrophic factor on impaired neurite development and mitochondrial function in dopaminergic neurons derived from dental pulp stem cells from children with attention deficit hyperactivity disorder. Biochemical and biophysical research communications. 2019;513(4):1048-54.

74. Marte A, Messa M, Benfenati F, Onofri F. Synapsins Are Downstream Players of the BDNF-Mediated Axonal Growth. Molecular neurobiology. 2017;54(1):484-94.

75. Studer L, Spenger C, Seiler RW, Othberg A, Lindvall O, Odin P. Effects of brain-derived neurotrophic factor on neuronal structure of dopaminergic neurons in dissociated cultures of human fetal mesencephalon. Experimental brain research. 1996;108(2):328-36.

76. Corominas-Roso M, Ramos-Quiroga JA, Ribases M, Sanchez-Mora C, Palomar G, Valero S, et al. Decreased serum levels of brain-derived neurotrophic factor in adults with attention-deficit hyperactivity disorder. The international journal of neuropsychopharmacology. 2013;16(6):1267-75.

77. Amiri A, Torabi Parizi G, Kousha M, Saadat F, Modabbernia MJ, Najafi K, et al. Changes in plasma Brain-derived neurotrophic factor (BDNF) levels induced by methylphenidate in children with Attention deficit-hyperactivity disorder (ADHD). Progress in neuro-psychopharmacology \& biological psychiatry. 2013;47:20-4.

78. Akay AP, Resmi H, Guney SA, Erkuran HO, Ozyurt G, Sargin E, et al. Serum brain-derived neurotrophic factor levels in treatment-naive boys with attention-deficit/hyperactivity disorder treated with methylphenidate: an 8-week, observational pretest-posttest study. European child \& adolescent psychiatry. 2018;27(1):127-35.

79. Miguel PM, Deniz BF, Confortim HD, de Almeida W, Bronauth LP, Vieira MC, et al. Methylphenidate treatment increases hippocampal BDNF levels but does not improve memory deficits in hypoxic-ischemic rats. Journal of psychopharmacology. 2020;34(7):750-8.

80. Oakes HV, DeVee CE, Farmer B, Allen SA, Hall AN, Ensley T, et al. Neurogenesis within the hippocampus after chronic methylphenidate exposure. Journal of neural transmission. 2019;126(2):2019.

81. Pieribone VA, Porton B, Rendon B, Feng J, Greengard P, Kao HT. Expression of synapsin III in nerve terminals and neurogenic regions of the adult brain. The Journal of comparative neurology. 
2002;454(2):105-14.

82. Pattabiraman PP, Tropea D, Chiaruttini C, Tongiorgi E, Cattaneo A, Domenici L. Neuronal activity regulates the developmental expression and subcellular localization of cortical BDNF mRNA isoforms in vivo. Molecular and cellular neurosciences. 2005;28(3):556-70.

83. Hong EJ, McCord AE, Greenberg ME. A biological function for the neuronal activity-dependent component of Bdnf transcription in the development of cortical inhibition. Neuron. 2008;60(4):610-24.

84. Palomer E, Martin-Segura A, Baliyan S, Ahmed T, Balschun D, Venero C, et al. Aging Triggers a Repressive Chromatin State at Bdnf Promoters in Hippocampal Neurons. Cell reports. 2016;16(11):2889900 .

85. Fukuchi M, Saito R, Maki S, Hagiwara N, Nakajima Y, Mitazaki S, et al. Visualization of activityregulated BDNF expression in the living mouse brain using non-invasive near-infrared bioluminescence imaging. Molecular brain. 2020;13(1):122.

86. . !!! INVALID CITATION !!! \{lchikawa, $1993 \# 15\}$.

87. Verstraelen P, Garcia-Diaz Barriga G, Verschuuren M, Asselbergh B, Nuydens R, Larsen PH, et al. Systematic Quantification of Synapses in Primary Neuronal Culture. iScience. 2020;23(9):101542.

88. Harrill JA, Chen H, Streifel KM, Yang D, Mundy WR, Lein PJ. Ontogeny of biochemical, morphological and functional parameters of synaptogenesis in primary cultures of rat hippocampal and cortical neurons. Molecular brain. 2015;8:10.

89. Gaven F, Marin P, Claeysen S. Primary culture of mouse dopaminergic neurons. Journal of visualized experiments : JoVE. 2014(91):e51751.

\section{Figures}




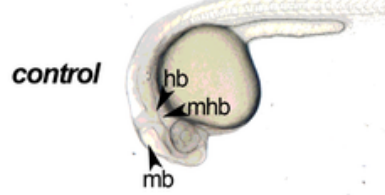

Syn III-MO

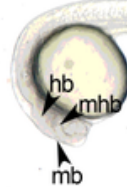

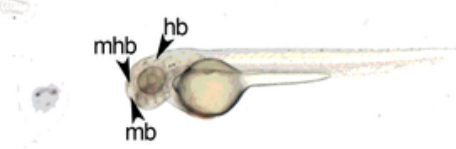

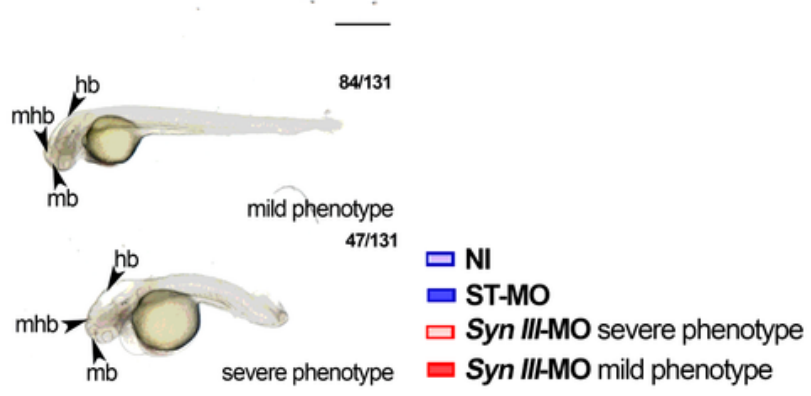

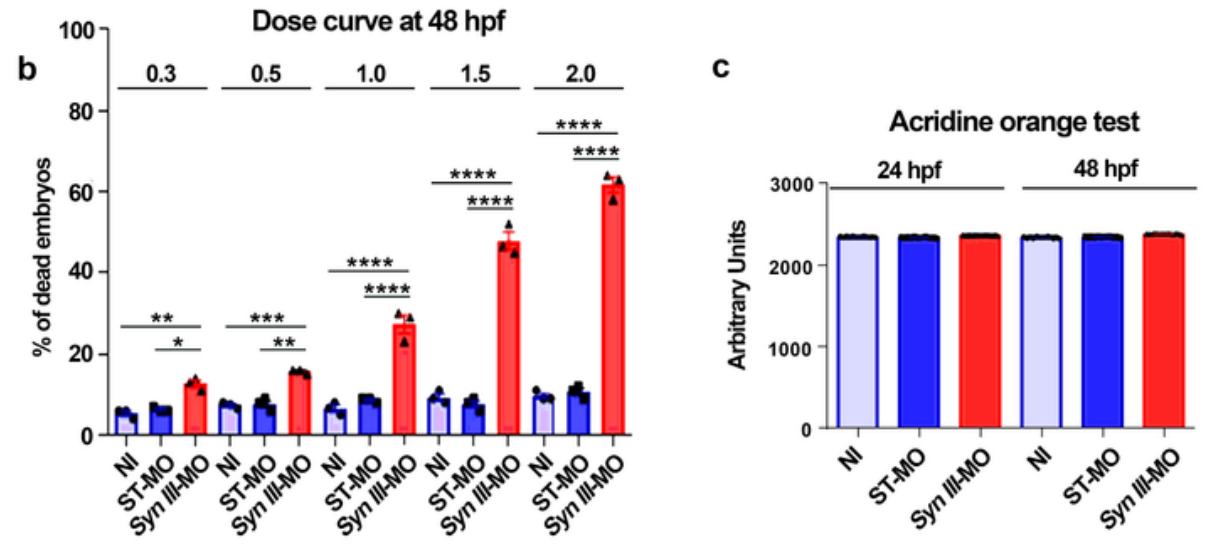
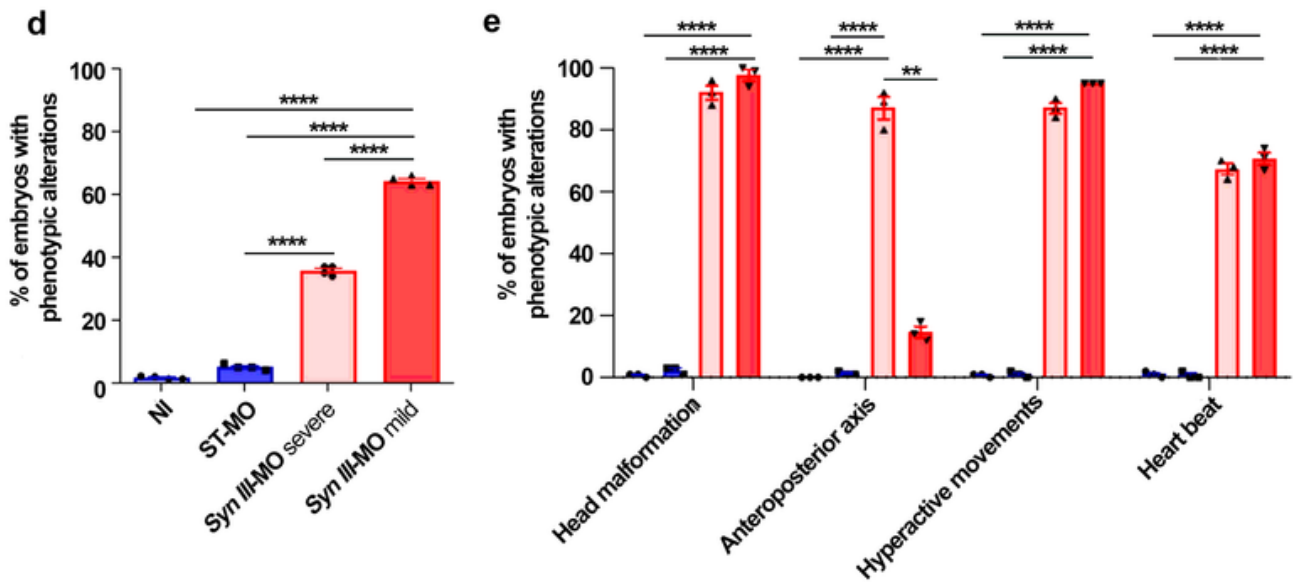

\section{Figure 1}

\section{Characterization of phenotypic alterations induced by Syn IIFMO injection in zebrafish}

a. Representative images of ST-MO- or Syn III-MO-injected zebrafish embryos at 24 and $48 \mathrm{hpf}$. Please note that the Syn III-MO-injected morphants exhibited either mild or severe phenotypic alterations (mild phenotype or severe phenotype) at $48 \mathrm{hpf}$. Scale bars, $500 \mu \mathrm{m}$. 
b. The graph shows the percentage of dead embryos following the injection of different doses of Syn II$\mathrm{MO}$ or ST-MO when compared to control non-injected (NI) embryos. A significant progressing increase in the percentage of dead embryos was observed after the injection of ascending doses $(0.3,0.5,1.5,1.5$ and $2 \mathrm{pmol} / \mathrm{embryo})$ of Syn III-MO (* $\mathrm{p}<0.05, * \star \mathrm{p}<0.01$, ${ }^{* \star *} \mathrm{p}<0.001, * \star \star * \mathrm{p}<0.0001$ One-way ANOVA + Newman-Keuls multiple comparisons test, $n=3$ experimental replicates represent the $\%$ mean of dead embryos from each group from 3 experimental sessions including at least 20 embryos for each experimental condition).

c. The graph shows the results from acridine orange assay that was used to probe the incidence of apoptotic cell death in the embryos injected with $1.0 \mathrm{pmol} / \mathrm{embryo}$ of ST-MO or Syn III-MO when compared to $\mathrm{Nl}$ embryos at 24 and $48 \mathrm{hpf}$. The y-axis represents the acridine orange fluorescence intensity of embryos in arbitrary units. Please note that Syn II-MO injection was not associated with apoptotic cell death at 24 or $48 \mathrm{hpf}$ (One-way ANOVA + Newman-Keuls multiple comparisons test. $n=4$ experimental replicates represent the mean fluorescence intensity from each group in 4 experimental sessions including at least 10 embryos per each experimental condition).

d. The graph shows the percentage distribution of NI, ST-MO- and Syn III-MO-injected embryos with abnormal morphology at $48 \mathrm{hpf}$. The Syn III-MO injected were categorized in mild or severe phenotype. The number of morphants with mild phenotype was significantly higher than that of the embryos with severe phenotype. ( ${ }^{\star \star *} p<0.0001$; one-way ANOVA + Newman-Keuls multiple comparisons test, $n=3$ experimental replicates represent the \% mean of dead embryos from each group from 3 experimental sessions including at least 20 embryos per each experimental condition).

e. Graph showing the percentage of NI, ST-MO- or mild and severe Syn III-MO-injected embryos exhibiting head malformations, anteroposterior axis alterations, hyperactive movements or abnormal heartbeat at $48 \mathrm{hpf}$. A significant higher percentage of either mild or severe Syn II-MO-injected morphants exhibited head malformations, hyperactive movements and heartbeat. Anteroposterior axis alterations frequency

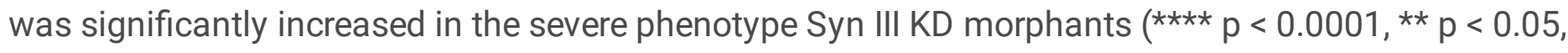
one-way ANOVA + Newman-Keuls multiple comparisons test, $n=3$ experimental replicates represent the $\%$ mean of dead embryos from each group from 3 experimental sessions including at least 20 embryos per each experimental condition).

\section{Figure 2}

\section{The expression of $n g n 1$, Islet-1 and $g f a p$ is reduced in Syn IIFMO injected embryos}

a. Representative images of ST-MO and Syn II-MO-injected zebrafish embryos hybridized with $n g n 1$ at 16 hpf and 24 hpf. Abbreviations: hb, hindbrain; cg, cranial ganglia; t, telencephalon; d, diencephalon. 16 hpf scale bar, $200 \mu \mathrm{m} ; 24 \mathrm{hpf}$ scale bar, $500 \mu \mathrm{m}$. 
b-c. Graphs show the quantification of $n g n 1$ signal at $16 \mathrm{hpf}$ (b) and $24 \mathrm{hpf}$ (c) expressed as mean intensity values in arbitrary units (A.U.). Please note the significant decrease of the mean intensity value of Syn III-MO-injected embryos when compared to control embryos (***, p $<0.001$, unpaired Student's ttest, $n=12$ embryos per each condition).

d-e. Representative images showing $30 \mathrm{hpf}$ embryos hybridized with Islet- 1 (d) and gfap (e), scale bar = $200 \mu \mathrm{m}$ for all the panels. Abbreviations: $d$, diencephalon; f: forebrain; hb, hindbrain; hbn, hindbrain neurons; mhb, midbrain hindbrain boundary; mb, midbrain; on: optic nerve; t, telencephalon.

f-g. Graphs showing the quantification of Islet-1 (f) and gfap (g) signal expressed as mean intensity values. Syn III-MO-injected embryos exhibited a significant decrease of both Islet-1 and gfap when compared to control embryos (** $p<0.001$ and ${ }^{* \star} p<0.01$, unpaired Student's $t$-test, $n=6-15$ embryos per each condition). 

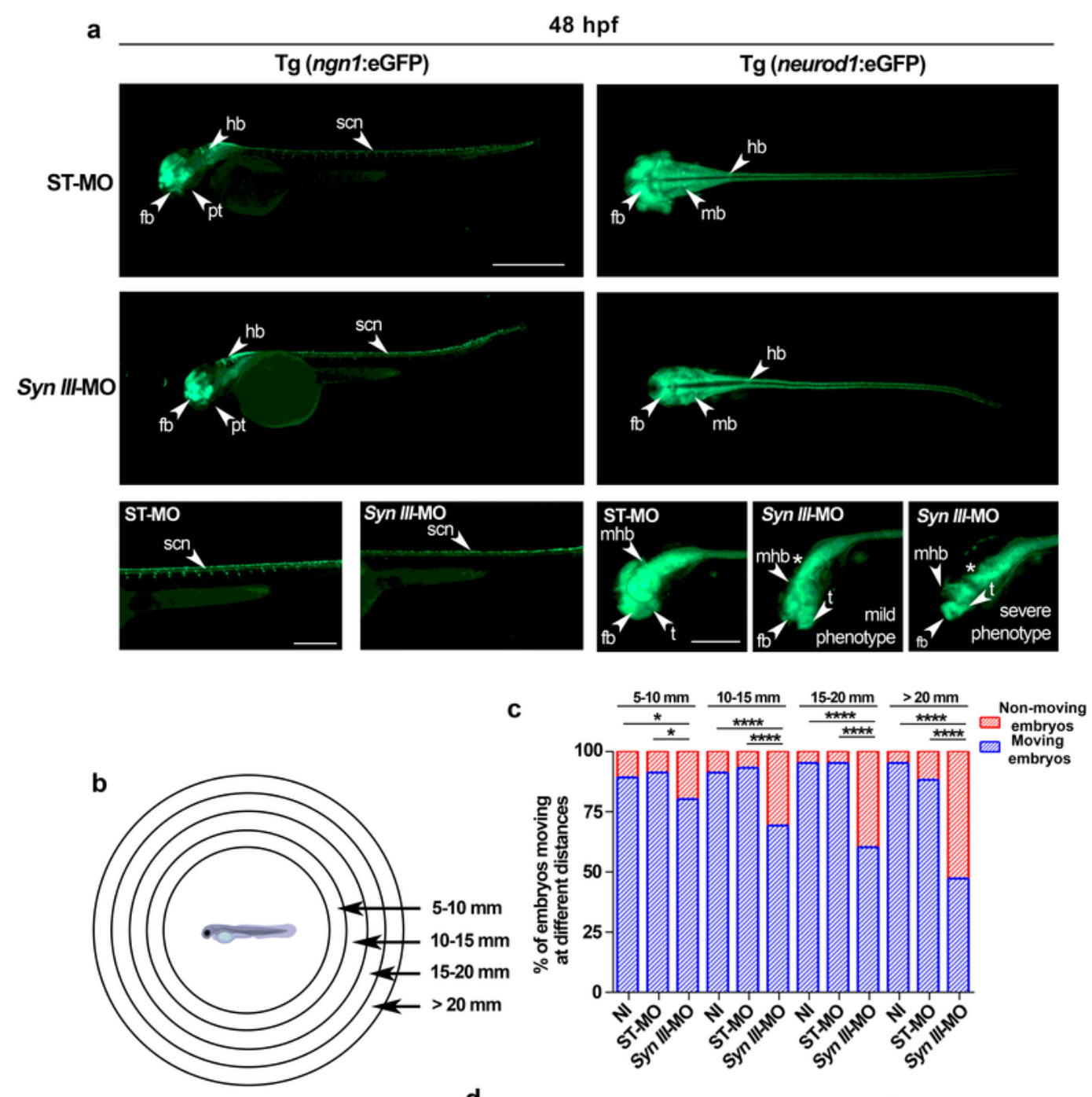

Distance travelled

d

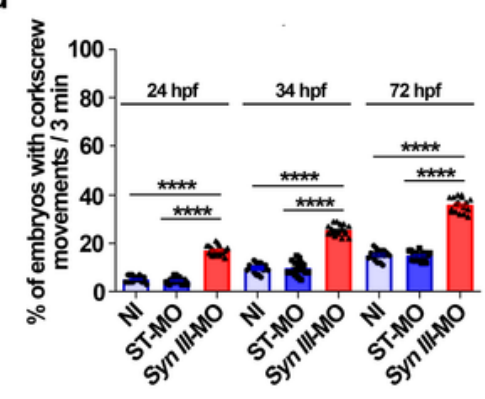

e

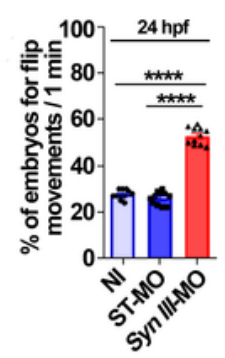

Figure 3

Syn IIIMO injection affects $\mathrm{Tg}$ (ngn:eGFP) and $\mathrm{Tg}$ (neurod1:eGFP) embryos neurodevelopment and behavior

a. Representative images showing $n g n 1$ and neurod 1 dependent eGFP fluorescence in the embryos injected with ST-MO or Syn III-MO. Representative lateral views of $\operatorname{Tg}(n g n 1: \mathrm{eGFP})$ embryos injected with 
ST-MO or Syn III-MO at $48 \mathrm{hpf}$. Representative dorsal and lateral views of $\mathrm{Tg}$ (neurod1:eGFP) embryos either injected or not with ST-MO or Syn III-MO at $48 \mathrm{hpf}$. Dorsal/lateral view scale bar, $500 \mu \mathrm{m}$. Tail/head scale bars $=250 \mu \mathrm{m}$. The asterisk in the high magnification panels of the head of Syn III-MO-injected embryos indicates the midbrain/hindbrain regions exhibiting a clear reduction of the eGFP signal in the morphants. Abbreviations: fb, forebrain; hb, hindbrain, mhb, midbrain-hindbrain boundary; $t$, telencephalon; pt, posterior tuberculum; scn, spinal cord neurons.

b. Schematic representation of the method for the evaluation of the distance travelled in the touch-evoked test.

c. The graph shows the analysis of the swimming performance of embryos at $72 \mathrm{hpf}$ in the touch-evoked test. A significant progressive decrease in the \% of syn3 KD morphants when compared to NI or ST-MOinjected embryos was detected $\left(* p<0.05,{ }^{\star}{ }^{\star * \star} p<0.0001\right.$, one-way ANOVA + Newman-Keuls postcomparison test, the results are representative of 3 independent experiments with a total of 40 embryos per each group).

d. Graph shows the percentage of NI, ST-MO or Syn III-MO-injected embryos exhibiting corkscrew movements during a period of 3 minutes at 24,48 or $72 \mathrm{hpf}$. A significant increase in the percent of syn3 $\mathrm{KD}$ morphants showing with corkscrew movement when compared to $\mathrm{NI}$ or ST-MO-injected embryos was

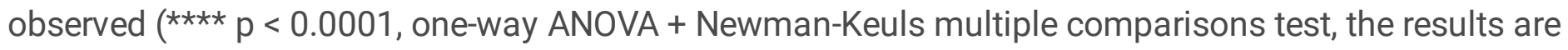
representative of 3 independent experiments with a total of 40 embryos per each group).

e. The graph shows the number of spontaneous flipping movements during 3-min observation in embryos at $24 \mathrm{hpf}$. A significant increase in this parameter was observed in the Syn II-MO-injected embryos when compared to NI or ST-MO-injected ones ( $* \star \star \star ~ p ~<0.0001$, one-way ANOVA + Newman-Keuls multiple comparison test, the results are representative of 3 independent experiments with a total of 40 embryos per each group). 
a

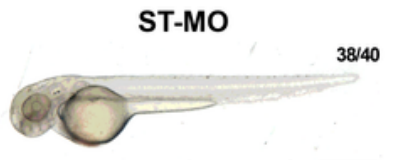

b

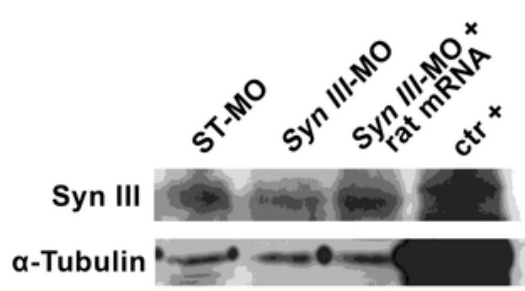

Syn III-MO

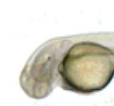

Syn III-MO + rat mRNA

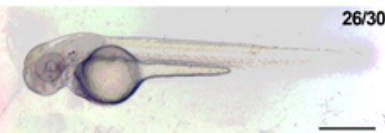

c

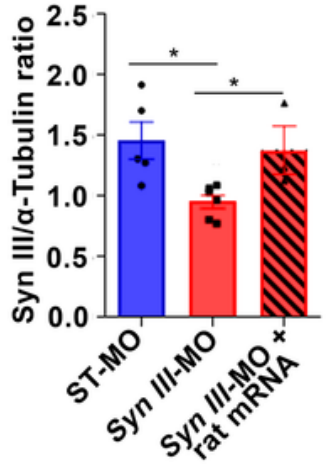

d

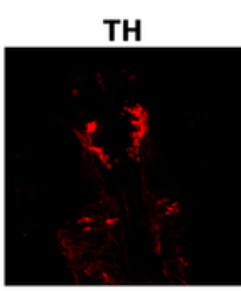

merged

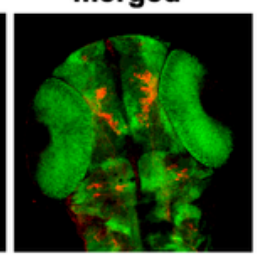

e
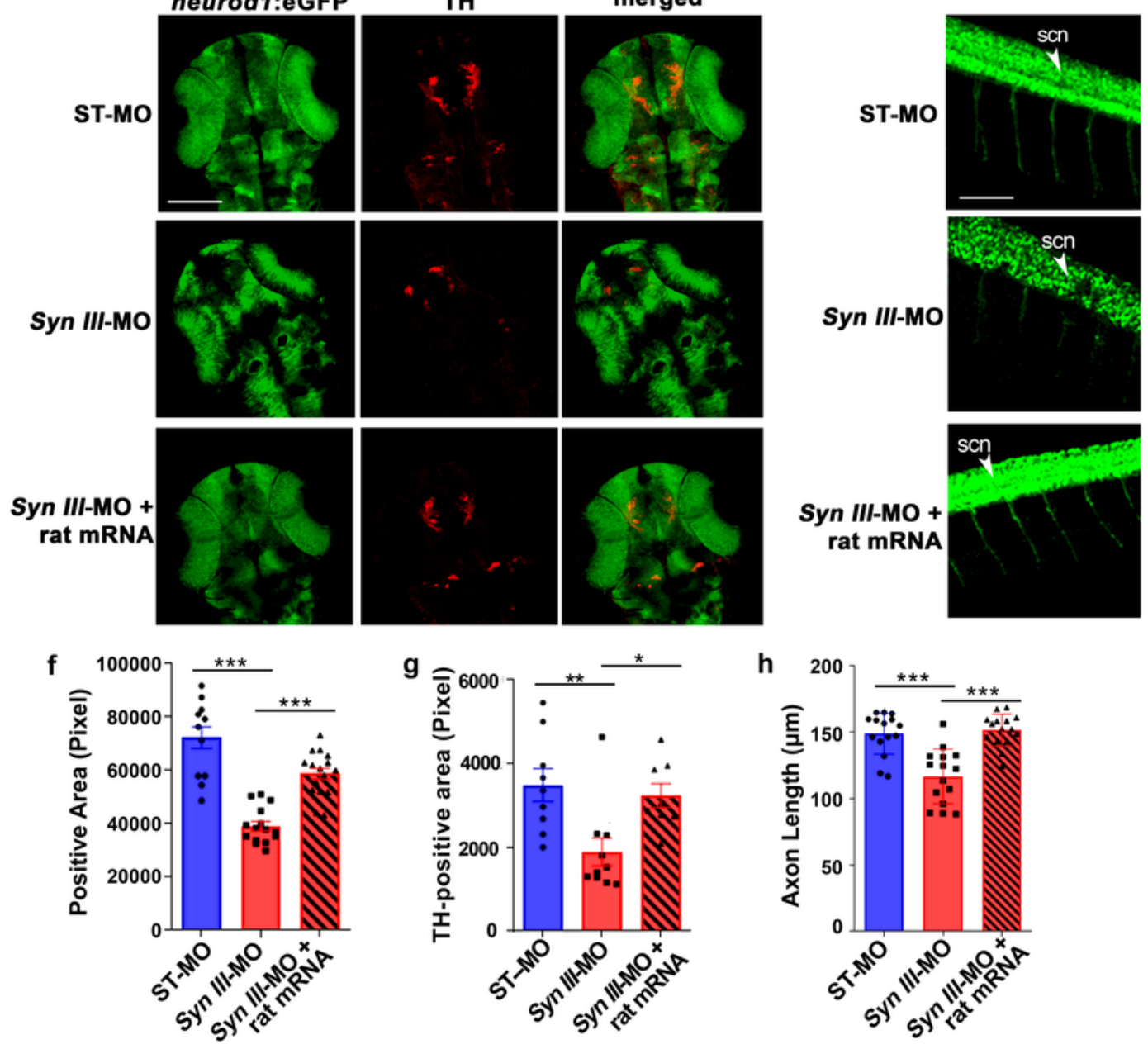

Figure 4

The neurodevelopmental deficits rescued by rat Syn III mRNA expression of Syn IIIMO-injected $\mathrm{Tg}$ (neurod1:eGFP) embryos involve TH-positive dopaminergic neurons

a. Brightfield images showing embryos injected with non-silencing ST-MO, Syn III-MO or Syn II-MO and rat mRNA (Syn III-MO + rat mRNA). Scale bars, $100 \mu \mathrm{m}$. 
b. Representative images from a western blot from protein extracts of ST-MO-, Syn III-MO- or Syn III-MO + rat mRNA-injected $\mathrm{Tg}$ (neurod1:eGFP) embryos. The positive control is a protein extract obtained from the striatum of twelve-month-old C57BL/6J wt mice. Alpha-Tubulin bands are representative of the equal loading of the different samples.

c. Histograms showing the ratio between the optical density (o.d.) of Syn III and a-Tubulin of ST-MO, Syn III-MO and Syn III-MO + rat mRNA-injected Tg(neurod1:eGFP) embryos. Please note the statistically significant decrease of Syn III in the embryos exposed to Syn III KD when compared to either control or Syn III-MO + rat mRNA (* $p<0.05$, One-way Anova + Newman-Keuls multiple comparisons test, $n=5$ zebrafish protein pools per each experimental condition).

d. Representative images showing TH immunostaining performed on $48 \mathrm{hpf} \mathrm{Tg}$ (neurod1:eGFP) embryos injected with ST-MO, Syn III-MO or Syn III-MO + rat mRNA. Scale bar, $200 \mu \mathrm{m}$.

e. Representative images showing lateral spinal cord views of $48 \mathrm{hpf} \mathrm{Tg}$ (neurod1:eGFP) embryos injected with ST-MO, Syn III-MO or Syn III-MO + rat mRNA. Scale bar, $200 \mu \mathrm{m}$. Abbreviations: scn, spinal cord neurons.

f. Graph is showing the quantification of the area of the eGFP-positive signal in the diencephalon. ${ }^{* \star} \mathrm{p}<$ 0.001, one-way ANOVA + Newman-Keuls multiple comparisons test. $n=11-15$ zebrafish embryos per each condition.

g. Graph is showing the TH-immunopositive area (in pixel) of the $48 \mathrm{hpf} \mathrm{Tg}$ (neurod1:eGFP) embryos injected with ST-MO, Syn III-MO or Syn III-MO + rat mRNA. Please note that the expression of rat Syn III rescued the developmental deficits of TH-positive neurons in Syn III KD embryos (** $p<0.01, * p<0.05$; One-way ANOVA + Newman-Keuls multiple comparisons test. $n=8-10$ zebrafish embryos per each experimental condition).

h. Graph is showing axonal length of spinal cord neurons (expressed in $\mu \mathrm{m}$ ) of ST-MO-, Syn II-MO- or Syn III-MO + rat mRNA-injected Tg(neurod1:eGFP) embryos at $48 \mathrm{hpf}$. The injection of rat Syn III also rescued the reduction of spinal cord neurons axonal projections in Syn III KD embryos (*** $p<0.001$ Syn III-MO or Syn III-MO + rat mRNA vs control. One-way ANOVA + Newman-Keuls multiple comparisons test. $n=15$ zebrafish per each condition). 


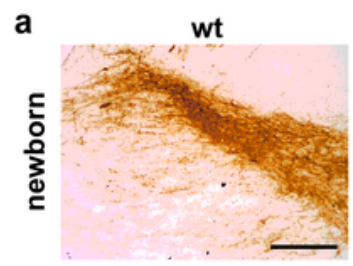

\section{Syn III ko}
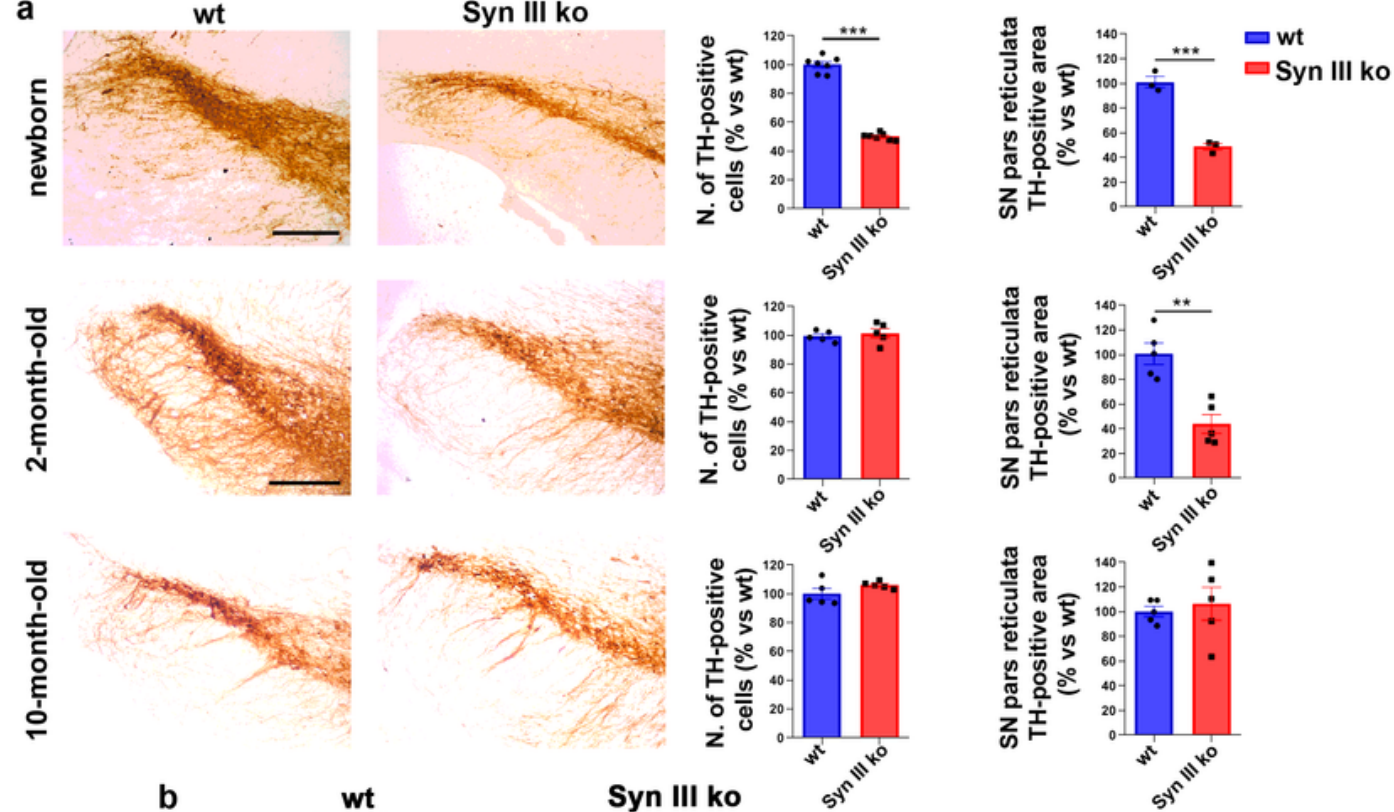

b

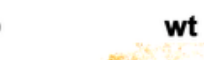

Syn III ko
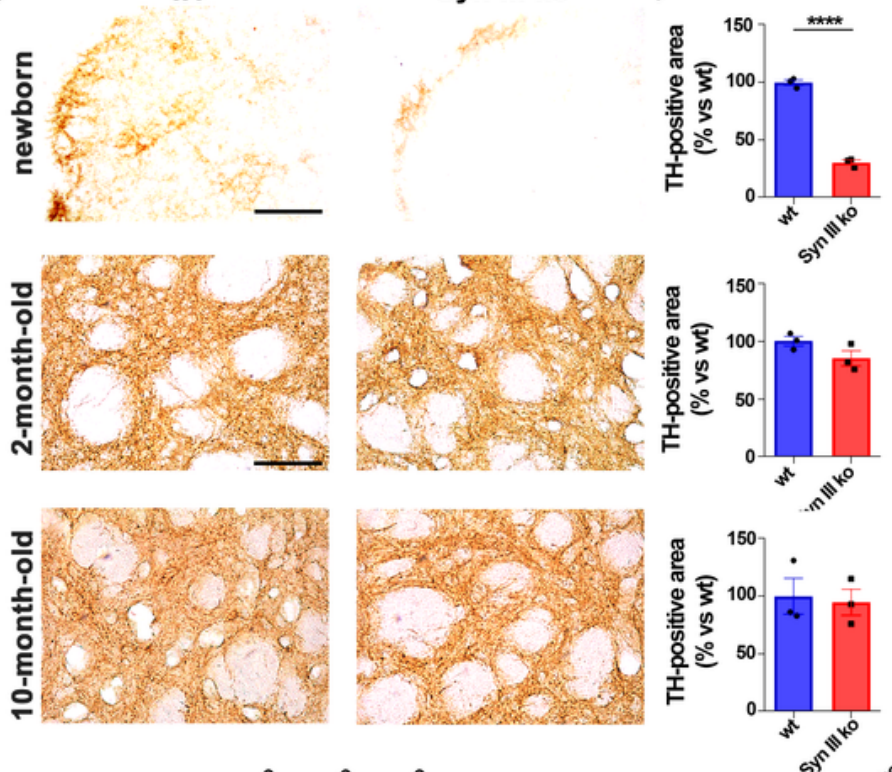

c

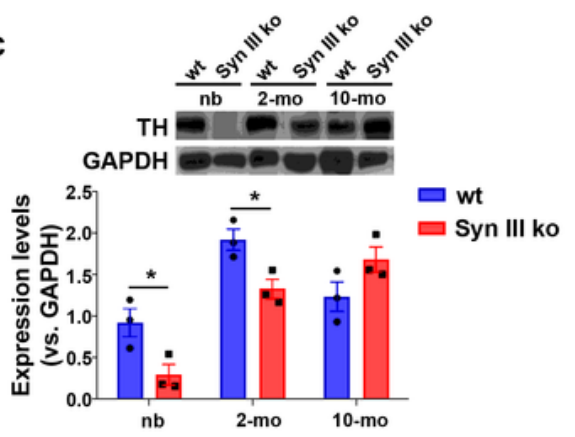

d

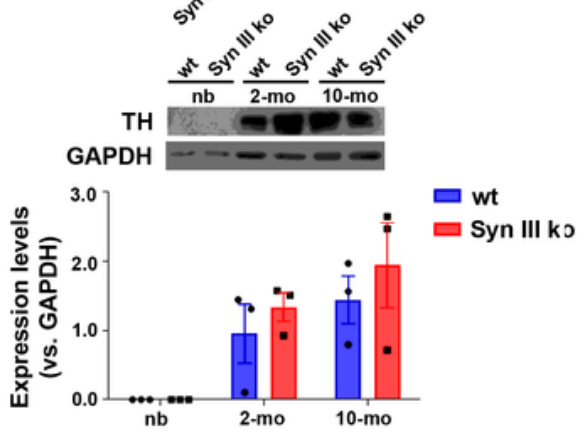

\section{Figure 5}

The reduction of nigrostriatal neurons development in newborn Syn III ko mice is progressively recovered in adult mice

a. The number of TH-positive neurons in the SN of wt and Syn III ko mice was evaluated at 0,2 and 10 months of age. Graphs are showing the percent changes in TH-positive cell numbers of Syn III ko vs wt 
mice evaluated by stereological analysis of $\mathrm{SN}$ slices. Please note the significant reduction of TH-positive neurons in newborn mice ( ${ }^{* \star} p<0.01$, unpaired Student's t-test, $n=3$ per each group). The analysis of THimmunopositive area in the pr of wt and Syn III ko mice (expressed as the percent change vs the agematched wt mice) showed that the absence of Syn III reduced this parameter in both newborn and 2month-old mice (*** $p<0.001, * \star p<0.01$, unpaired Student's $t$ test, $n=5$ animals per each group). Scale bar newborn mice: $100 \mu \mathrm{m}$; scale bar 2 and 10 month-old mice: $150 \mu \mathrm{m}$.

b. Representative images showing striatal TH-positive fibers of newborn, 2-month- or 10-month-old wt and Syn III ko animals. Graphs show the percent changes in the striatal TH-positive area in the Syn III ko

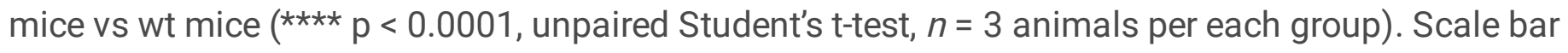
newborn mice: $120 \mu \mathrm{m}$; scale bar 2 and 10 month-old mice: $200 \mu \mathrm{m}$.

c. Representative images showing TH-immunopositive bands from western blot analysis of Syn III ko or wt mouse midbrain protein extracts. The graph shows that Syn III levels were significantly reduced in the midbrain of newborn (nb) and 2-month-old Syn III ko mice when compared to wt littermates. No difference in TH levels was observed at 10 months of age. Data are expressed as TH protein levels normalized vs GAPDH expression ( ${ }^{*} p<0.05$, two-way ANOVA + Bonferroni's multiple comparisons test, $n$ $=3$ animals per each group).

d. Western blot analysis of striatal protein extracts from Syn III ko and wt mice showed that TH protein levels did not exhibit significant changes at 0 (nb), 2 and 10 months of age. Two-way ANOVA + Bonferroni's multiple comparisons test ( $n=3$ animals per each group). 

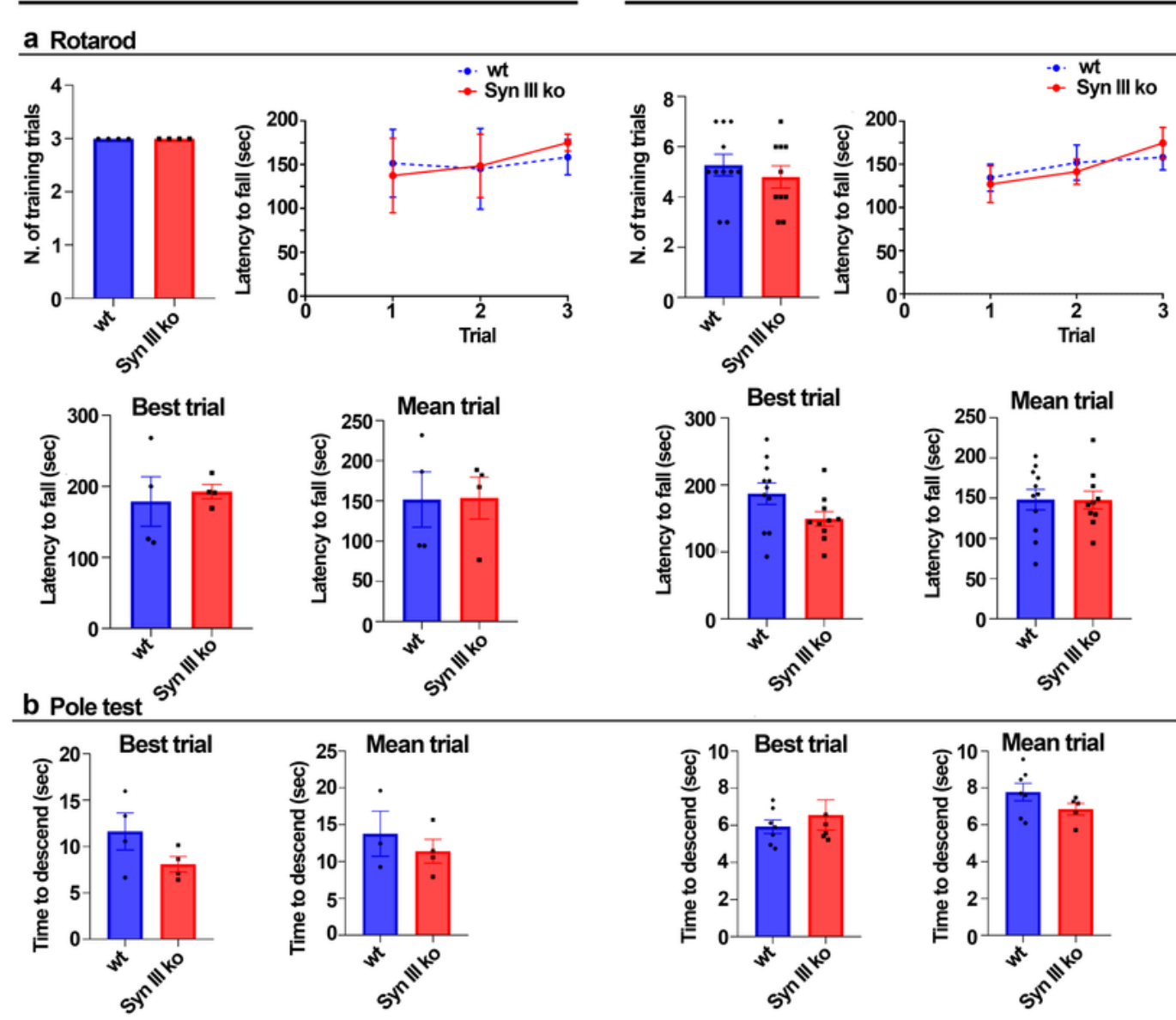

\section{Figure 6}

Behavioral analysis of 2 and 10-month-old wt and Syn III ko mice

a. Results from the Rotarod Test. The graphs show the analysis of the number of training trials, the latency to fall of the best trial, the mean trial and the diagram of the latency to fall in each trial. Please 
note that no difference in these parameters was detected between wt and Syn III ko mice at 2 or 10 months of age (Student's t-test, $\mathrm{n}=3$ mice for each group).

b. The graphs show the results of the pole test. No differences in the time to descend the pole was detected between the Syn III ko or wt mice in either the best or mean trial (Student's t-test, $\mathrm{n}=3$ mice for each group).
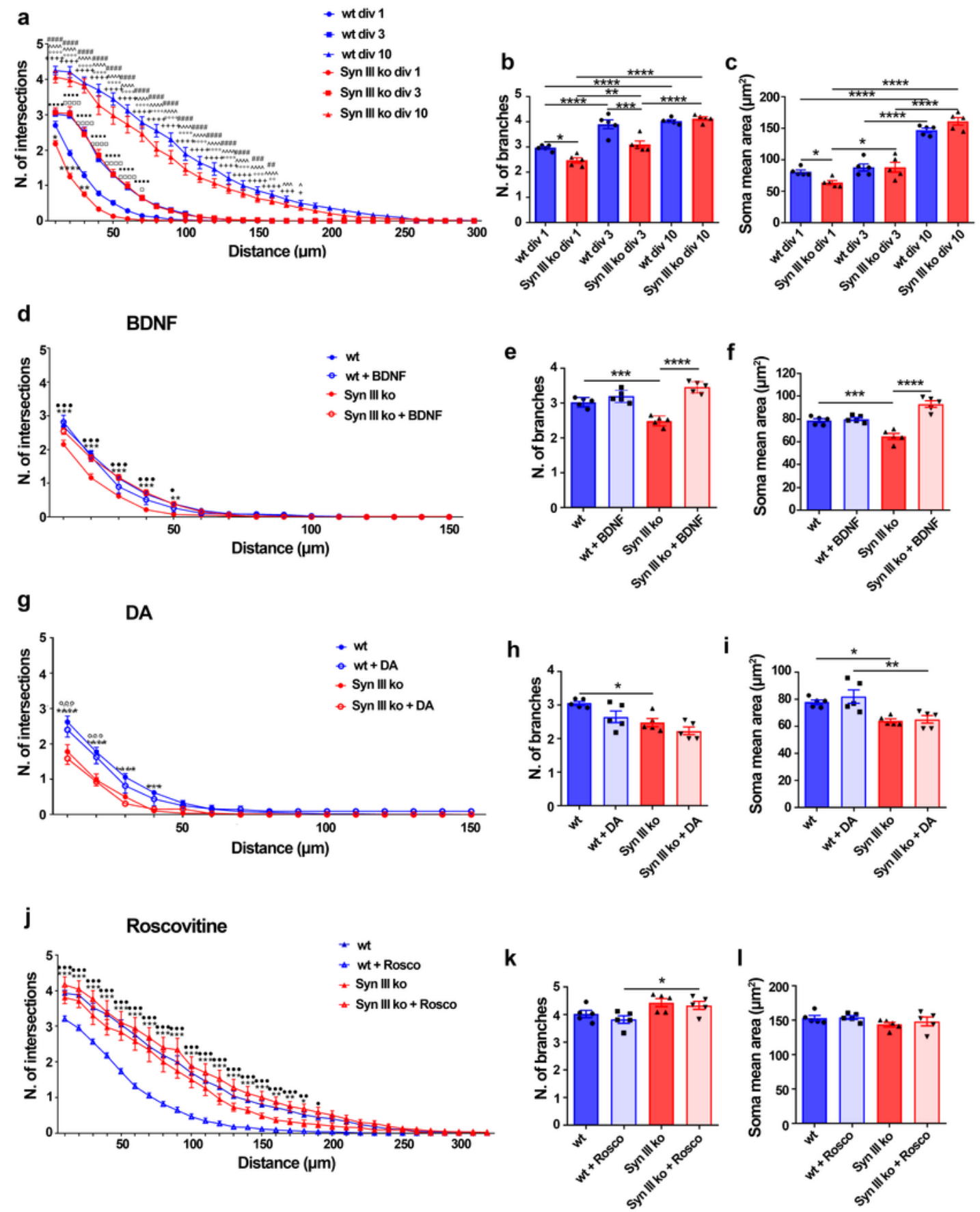


\section{Figure 7}

\section{Mesencephalic neurons derived from Syn III ko mice exhibit neurodevelopmental deficits characterized by altered BDNF-mediated and disrupted Cdk5-dependent dendritic arborization}

a. Results from Sholl analysis evaluating the number of intersections between the neuronal projections of primary midbrain $\mathrm{TH}$-positive cells and concentric circles show a significant decrease of this parameter in div 1 Syn III ko neurons when compared to wt neurons ( ${ }^{\star * \star} p<0.001$, $* \star p<0.01$, ${ }^{*} p<0.05$; two-way ANOVA + Bonferroni's multiple comparisons test).

A significant increase in the number of intersections was observed in div 10 when compared to div 3 ( $\wedge$ $\left.<0.05,{ }^{\wedge \wedge \wedge} p<0.001,{ }^{\wedge \wedge \wedge \wedge} p<0.0001\right)$ or div 1 wt neurons $(+p<0.05,+++p<0.001,++++p<0.0001)$ as well as in $\operatorname{div} 10$ to when compared to $\operatorname{div} 3(\# \# p<0.01$, \#\#\# $p<0.001$, \#\#\#\#p<0.0001) or div 1 Syn III ko neurons $\left({ }^{\circ \circ} p<0.01,{ }^{\circ 00} p<0.001,{ }^{\circ 000} p<0.0001\right)$. In Syn III ko neurons a significant increase in the number of intersections at div 3 when compared to div 1 neurons was also detected $(\mathbf{\square} \square \mathbf{D}<0.0001$, $\square \mathrm{p}<0.05, \square \square \square \square \mathrm{p}<0.0001$, in wt neurons). Data were analyzed by one-way ANOVA + Newman-Keuls multiple comparisons test. $n=5$ means that plotted values are the mean values deriving from 5 experiments analyzing $30 \mathrm{TH}$-positive cells from primary midbrain neuronal cells cultures of either Syn III ko or wt mice.

b. The analysis of the number of branches stemming from the primary midbrain neuronal cell bodies show a significant decrease in this parameter in $\operatorname{div} 1(* p<0.05)$ and $\operatorname{div} 3(* \star *<0.001)$ TH-positiveneurons from Syn III ko when compared to wt mice. Data were analyzed by one-way ANOVA + NewmanKeuls multiple comparisons test. $n=5$ means that plotted values are the mean values deriving from 5 experiments analyzing $30 \mathrm{TH}$-positive cells from primary midbrain neuronal cells cultures of either Syn III ko or wt mice.

c. The analysis of the mean soma area of TH-positive primary midbrain neurons show a significant decrease in div 1 Syn III ko when compared to wt cells ( $p<0.05$, one-way ANOVA + Newman-Keuls multiple comparison test). $n=5$ means that plotted values are the mean values deriving from 5 experiments analyzing $30 \mathrm{TH}$-positive cells from primary midbrain neuronal cells cultures of either Syn III ko or wt mice.

d. Sholl analysis showed that BDNF treatment restored the reduction in the number of intersections in Syn III ko but not in the wt TH-positive cells (*** $p<0.001$, $* \star p<0.01$, Syn III ko vs wt untreated neurons and $\cdots p<0.001, \cdot p<0.05$, untreated vs treated Syn III ko neurons, two-way ANOVA + Bonferroni's multiple comparisons test). $n=5$ means that plotted values are the mean values deriving from 5 experiments analyzing $30 \mathrm{TH}$-positive cells from primary midbrain neuronal cells cultures of either Syn III ko or wt mice).

e-f. BDNF treatment also recovered the reduction in the number of branches and mean soma area of Syn III ko neurons ( ${ }^{\star \star \star} p<0.001$, Syn III ko vs wt untreated neurons, ${ }^{\star \star \star \star} p<0.0001$, untreated vs treated Syn 
III ko neurons, one-way ANOVA + Bonferroni's multiple comparisons test). $n=5$ means that plotted values are the mean values deriving from 5 experiments analyzing $30 \mathrm{TH}$-positive cells from primary midbrain neuronal cells cultures of either Syn III ko or wt mice.

g. Sholl test showed that DA treatment was not effective in improving the number of intersections in Syn III ko TH-positive cells (*** $p<0.001$ and ${ }^{* * * *} p<0.0001$ vs wt untreated neurons and ${ }^{\circ 00} p<0.001$, vs wt neurons, two-way ANOVA + Bonferroni's multiple comparisons test).

h-i. DA treatment did not either improve the branching or mean soma are of the TH-positive midbrain neurons from Syn III ko mice (* $p<0.05$, Syn III ko vs wt untreated neurons, ${ }^{*} p<0.01$, Syn III ko vs wt DA-treated neurons, one-way ANOVA + Newman-Keuls multiple comparisons test).

j. Sholl analysis showed that the roscovitine treatment reduced number of intersections of wt TH-positive cells, but not that of Syn III ko neurons ( $* * * p<0.001$, $* * p<0.01$, $* p<0.05$, untreated vs treated wt neurons and $\cdots p<0.001, \cdots p<0.01, \cdot p<0.05$, wt vs Syn III ko neurons; two-way ANOVA + Bonferroni's multiple comparisons test).

k-I. The treatment of div 3 primary mouse midbrain neurons with Roscovitine for $24 \mathrm{~h}$ did not affect the number of branches and the mean soma area of wt and Syn III ko neurons (one-way ANOVA + NewmanKeuls Multiple Comparison Test). $\mathrm{n}=5$ means that plotted values are the mean values deriving from 5 experiments analyzing $30 \mathrm{TH}$-positive cells from primary midbrain neuronal cells cultures of either Syn III ko or wt mice. 

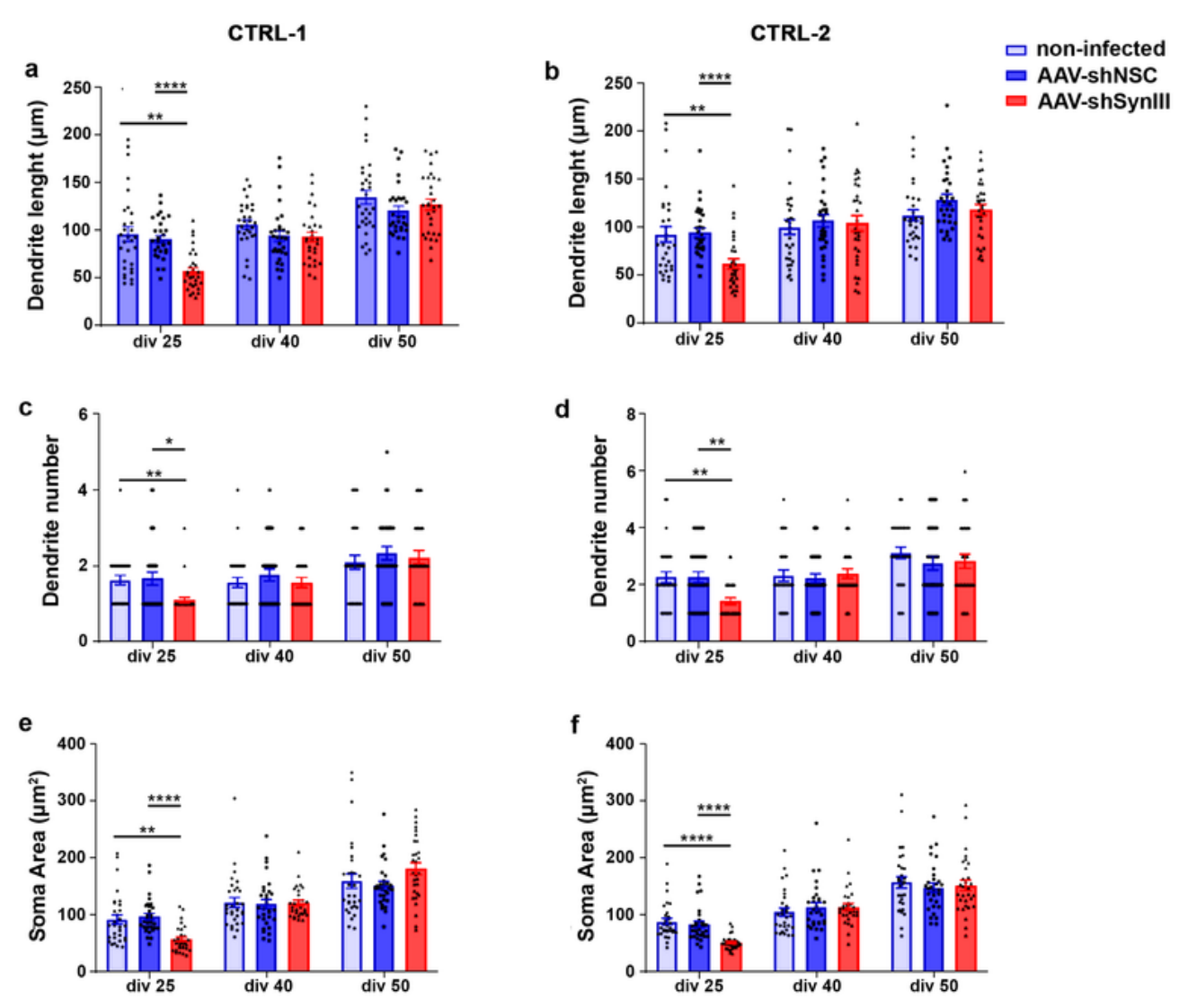

\section{Figure 8}

AAV-mediated Syn III gene silencing impaired the early stages of development of iPSCs-derived mDN

a-b. The graphs show the analysis of the primary dendrite length (expressed in $\mu \mathrm{m}$ ) in control and AAVshSynlll- or AAV-shNSC-infected mDN produced from CTRL-1 (a) and CTRL-2 (b) iPSCs clones at div 25, 40 and 50 . Please note the statistically significant decrease of primary dendrite lengths in the AAV- 
shSynlll-infected mDN when compared to both control and AAV-shNSC-infected cells at 25 DIV (** $p<$ $0.01, * \star \star \star p<0.001$; two-way ANOVA + Bonferroni's multiple comparisons test). No changes were observed at div 40 or $50 . n=30$ cells per each experimental condition.

c-d. The graphs show the analysis of the dendrites number in control and AAV-shSynIII- or AAV-shNSCinfected mDN produced from CTRL-1 (c) and CTRL-2 (d) iPSCs clones at div 25, 40 and 50. A significant decrease in the number of dendrites at div 25 was observed in the AAV-shSynlll-infected mDN when compared to both control and AAV-shNSC-infected cells $\left({ }^{*} p<0.05\right.$, ${ }^{* *} p<0.01$; two-way ANOVA + Bonferroni's multiple comparisons test). No changes were observed at div 40 or $50 . n=30$ cells per each condition.

ef. The graphs show the analysis of the area of the soma of $\mathrm{mDN}$ (expressed in $\mu \mathrm{m}^{2}$ ) from control and AAV-shSynlll- or AAV-shNSC-infected mDN produced from CTRL-1 (e) and CTRL-2 (f) iPSCs clones at div 25, 40 and 50. A significant decrease in the mean soma area was detected in the AAV-shSynlll-infected $\mathrm{mDN}$ at div 25 when compared to control (** $p<0.01$ and $* \star \star * ~ p<0.0001)$ or AAV-shNSC-infected cells

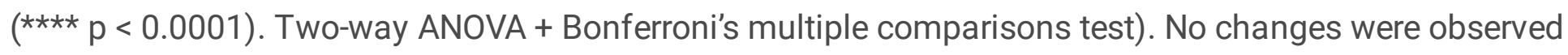
at div 40 or $50 . n=30$ cells per each condition.

\section{Supplementary Files}

This is a list of supplementary files associated with this preprint. Click to download.

- Onlineresource1.mp4

- Onlineresource10.pdf

- Onlineresource2.mp4

- Onlineresource3.mp4

- Onlineresource4.mp4

- Onlineresource5.pdf

- Onlineresource6.pdf

- Onlineresource7.mp4

- Onlineresource8.mp4

- Onlineresource9.pdf

- Supplementaryinformation.pdf 